\title{
Intestinal permeability - a new target for disease prevention and therapy
}

Stephan C Bischoff ${ }^{1 *}$, Giovanni Barbara², Wim Buurman ${ }^{3}$, Theo Ockhuizen ${ }^{4}$, Jörg-Dieter Schulzke ${ }^{5}$, Matteo Serino ${ }^{6}$, Herbert Tilg ${ }^{7}$, Alastair Watson ${ }^{8}$ and Jerry M Wells ${ }^{9}$

\begin{abstract}
Data are accumulating that emphasize the important role of the intestinal barrier and intestinal permeability for health and disease. However, these terms are poorly defined, their assessment is a matter of debate, and their clinical significance is not clearly established. In the present review, current knowledge on mucosal barrier and its role in disease prevention and therapy is summarized. First, the relevant terms 'intestinal barrier' and 'intestinal permeability' are defined. Secondly, the key element of the intestinal barrier affecting permeability are described. This barrier represents a huge mucosal surface, where billions of bacteria face the largest immune system of our body. On the one hand, an intact intestinal barrier protects the human organism against invasion of microorganisms and toxins, on the other hand, this barrier must be open to absorb essential fluids and nutrients. Such opposing goals are achieved by a complex anatomical and functional structure the intestinal barrier consists of, the functional status of which is described by 'intestinal permeability'. Third, the regulation of intestinal permeability by diet and bacteria is depicted. In particular, potential barrier disruptors such as hypoperfusion of the gut, infections and toxins, but also selected over-dosed nutrients, drugs, and other lifestyle factors have to be considered. In the fourth part, the means to assess intestinal permeability are presented and critically discussed. The means vary enormously and probably assess different functional components of the barrier. The barrier assessments are further hindered by the natural variability of this functional entity depending on species and genes as well as on diet and other environmental factors. In the final part, we discuss selected diseases associated with increased intestinal permeability such as critically illness, inflammatory bowel diseases, celiac disease, food allergy, irritable bowel syndrome, and - more recently recognized - obesity and metabolic diseases. All these diseases are characterized by inflammation that might be triggered by the translocation of luminal components into the host. In summary, intestinal permeability, which is a feature of intestinal barrier function, is increasingly recognized as being of relevance for health and disease, and therefore, this topic warrants more attention.
\end{abstract}

Keywords: Intestinal barrier, Intestinal permeability, Microbiota, Tight junctions, Obesity, Inflammatory bowel disease, Irritable bowel syndrome, Prebiotics, Probiotics, Gut health

\section{Introduction}

Why do we need a gut barrier? The intestinal barrier covers a surface of about $400 \mathrm{~m}^{2}$ and requires approximately $40 \%$ of the body's energy expenditure. It prevents against loss of water and electrolytes and entry of antigens and microorganisms into the body [1] while allowing exchange of molecules between host and environment and absorption of nutrients in the diet. Specialized adaptations

\footnotetext{
*Correspondence: bischoff.stephan@uni-hohenheim.de

'Department of Nutritional Medicine/Prevention, University of Hohenheim, Fruwirthstrasse 12, 70593 Stuttgart, Germany

Full list of author information is available at the end of the article
}

of the mammalian intestinal mucosa fulfill two seemingly opposing functions: firstly to allow a peaceful co-existence with intestinal symbionts without eliciting chronic inflammation and secondly to provide a measured inflammatory and defensive response according to the threat from pathogens $[2,3]$. It is a complex multilayer system, consisting of an external "physical" barrier and an inner "functional" immunological barrier. The interaction of these 2 barriers enables equilibrated permeability to be maintained [4]. To understand this complex barrier, not only the functions of its components, but also the processes of interactions of bacterial and other luminal components with cells and 
receptors of the host needs to be considered. Experimental data showed that disruption of the peaceful co-existence with intestinal symbionts at early life, and possibly even later in life, results in severe immunodeficiency and risk of disease [5-7]. Such findings support the hypothesis that the breakdown of intestinal barrier control mechanisms means danger and possibly disease.

What is the difference between intestinal barrier and intestinal permeability? The two terms have been used synonymously although they probably do not mean the same thing. A clear definition of such parameters as means to assess them is mandatory to avoid future confusion and to assess their impact for disease prevention and disease. In fact, intestinal permeability is a barrier feature closely linked to the intestinal commensal microbiota as well as to the elements of the mucosal immune system (Figure 1). Many factors can alter intestinal permeability such as gut microbiota modifications, mucus layer alterations, and epithelial damage, resulting in translocation of luminal content to the inner layers of the intestinal wall. Moreover, lifestyle and dietetic factors like alcohol and energy-dense food can increase intestinal permeability such as alcohol and energy-dense Western style diet [8-10].

What is the clinical significance of the intestinal barrier and intestinal permeability? There is now increasing evidence for the notion that loss of intestinal barrier functions can occur either abruptly, e.g. following a major trauma resulting in gram-negative sepsis and multi-organ failure (MOF), or gradually leading to chronic inflammatory diseases. During the last 30 years, almost 2000 publications appeared according to the PubMed database with a linear increase from approximately 10 publications a year in the eighties of last century to almost 100 at present. Although we learned over the past decade about the link between the intestinal barrier and diseases, the mechanisms are not precisely understood. For example, we have limited knowledge of what causes initially intestinal barrier dysfunction, and what prevents or restores it. The former

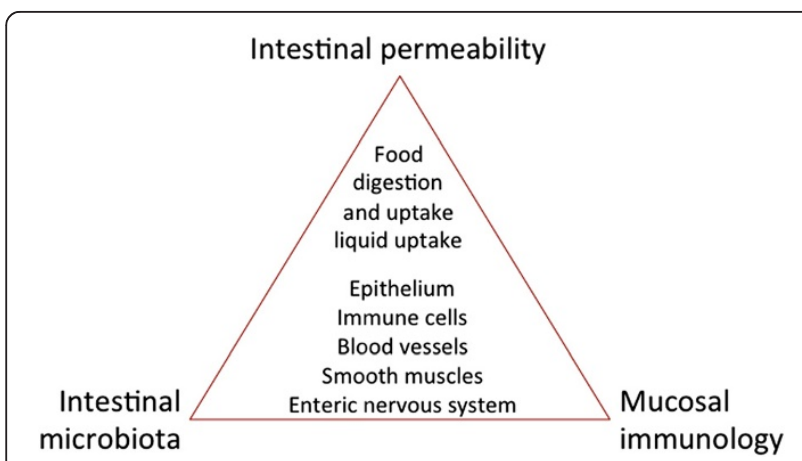

Figure 1 Relation between intestinal permeability, intestinal microbiota, and mucosal immunology. For details see text. might involve different events including virus infections, reduced perfusion of the mucosa, drugs, or changes in the microbiota [6]. New data suggest that intestinal barrier and intestinal microbiota play a role in many different diseases such as idiopathic liver fibrosis or intestinal dysbiosis the mechanism of which were largely unclear until recently [11-13].

Understanding that the intestinal barrier also means to have clear definitions, clear modes of assessment in vitro and in vivo in animal models and in humans, and clear strategies of how to perform human trials in this field. These topics have been extensively discussed within an expert panel in Frankfurt/Germany in June 2012. The major results are summarized and extended in the following text.

\section{Review}

Definition of intestinal permeability Definition of intestinal permeability and intestinal barrier

The term "mucosal barrier" was adopted by Cummings in 2004 to describe the complex structure that separates the internal milieu from the luminal environment [14]. The physical barrier includes a cellular component consisting of the vascular endothelium, the epithelial cell lining, and the mucus layer. Next to this physical barrier, chemical substances take part in the barrier function as well. They consist of digestive secretions, immune molecules, cell products like cytokines, inflammatory mediators and antimicrobial peptides, mainly produced by Paneth cells in the crypts of the small intestine. The intestinal microbiota is involved in metabolic processes and modulates the barrier, but does not represent a barrier function per se. On the other hand, the microbiota contributes to "intestinal health" - a term that is increasingly used although poorly defined. It may be described as a state of physical and mental well-being in the absence of gastro-intestinal complaints that require the consultation of a doctor, in the absence of indications of or risks for bowel disease and in the absence of confirmed bowel disease [6].

The terms "intestinal barrier" and "intestinal permeability" describe two different aspects of the same anatomical structure, the intestinal wall composed of four layers, the mucosa, the submucosa, the muscularis and the serosa. "Intestinal permeability" is a term shaped preferentially by electrophysiologists studying epithelial permeability in Ussing chambers using tissue explants from animals or humans for research purposes [15,16]. By extrapolating the Ussing chamber experiments to the in vivo situations, particular permeability tests have been developed such as the sugar test [17]. All these tests have in common that defined molecules such as electrolytes or sugars of different molecular weight are used for their capacity to enter and cross the epithelium or the mucosal layer, respectively and finally entering the submucosal site (Ussing chamber) or the blood (sugar test). 
"Intestinal barrier" is a term that has been established more recently by gastroenterologists, immunologists and microbiologists to emphasize the protective component of the gut shielding us against bacterial invasion, or invasion of other microorganisms and their toxins. Therefore, the means of assessing barrier functions were different to the approaches by the electrophysiologists and consisted of measuring translocation of bacteria or bacterial products like endotoxin from the gut into the portal vein, the liver or the systemic bloodstream. Likely, the mechanisms determining electrolyte fluxes, carbohydrate permeability and bacterial translocation are quite different; however, all approaches have in common that transfer of defined molecules across the intestinal wall (or parts of it) are measured. This knowledge might provide a basis for a definition of intestinal permeability, and also of normal and pathological intestinal permeability (Table 1).

Thus, according to the proposed definitions, intestinal permeability can be understood as a measurable feature of the intestinal barrier. The proposed definitions are related to above mentioned definition of gut health thought to be closely related to the intestinal barrier and intestinal permeability $[1,6]$.

The proposed definitions extent the more descriptive approach by Cummings et al. [14], who summarized: (1) The mucosal barrier is a complex structure that separates the internal milieu from the luminal environment. (2) Physically, the barrier includes cellular and stromal components, from the vascular endothelium to the epithelial cell lining, and the mucus layer, which consists of a gel formed by the interaction of various mucosal secretions, namely mucins, trefoil peptides and surfactant lipids. (3) Apart from the physical barrier, a chemical barrier exists consisting of digestive secretions, antimicrobial peptides, and other cell products (cytokines, inflammatory mediators etc.). (4) Also the intestinal microbiota can be considered as a barrier. (5) Finally immune functions and motility contribute to the barrier.

\section{Key element of the intestinal barrier affecting intestinal permeability}

In recent times, several important molecules and mechanisms of the intestinal barrier could be identified (Figure 2).
A single layer of epithelial cells form the main physical barrier between the lumen and mucosal tissues. The paracellular space is sealed by tight junctions (TJ) which regulate the flow of water ions and small molecules through the composition of claudins and other proteins in the junctional complex $[5,18,19]$. Below the tight junctions are the adherence junctions (AJ), which are important in cell-cell signaling and epithelial restitution as well as desmosomes supporting epithelial stability. TJ complexes consist of intra-membrane proteins, occludin and different members of the claudin family depending on the tissue and location that interlink within the paracellular space. Occludin and claudins and tricellulin link adjacent cells to the actin cytoskeleton through cytoplasmatic scaffolding proteins like Zonula occludens proteins [5]. Tricullin and occludin as well as a new protein named marvelD3, can be replaced in part by each other, but if all three are down-regulated or lacking, severe leakage occurs [20]. Claudins are a family of tight junction proteins consisting of sealing molecules and pores facilitating water and electrolyte loss. Zonula occludens proteins (ZO-1, ZO-2 and ZO-3) are important intracellular tight junction proteins, linking the cell cytoskeleton to the transmembrane tight junction proteins.

Whereas occludin and junction adhesion molecule have a regulatory role, claudins are transmembrane proteins mainly responsible for the intestinal barrier function. A central regulator of this epithelial barrier is the intestinal microbiota [21]. The importance of intact epithelial TJ is demonstrated again in inflammatory bowel diseases (IBD) $[16,22]$. For example, investigations in patients with Crohn's disease (CD) indicated impaired TJ complexity in sigmoid colon biopsies accompanied by a reduced expression of sealing claudin- $3,-5$ and -8 and occludin as well as a re-distribution of claudin-5 and -8 off the TJ [23]. Analogous changes were observed in ulcerative colitis (UC), comprising down-regulation of claudin-1 and -4 and occludin, but up-regulation of pore-forming claudin-2 [24].

The intestinal epithelium is renewed approximately every 5 days in humans due to proliferation and differentiation of multipotential stem cells located in the crypts of Lieberkühn [25]. At the tips of the villus and epithelial surface in the colon the fully differentiated cells undergo

\section{Table 1 Definitions}

\begin{tabular}{|c|c|}
\hline Intestinal barrier & $\begin{array}{l}\text { is a functional entity separating the gut lumen from the inner host, and consisting of mechanical elements (mucus, epithelial } \\
\text { layer), humoral elements (defensins, lgA), immununological elements (lymphocytes, innate immune cells), muscular and } \\
\text { neurological elements }\end{array}$ \\
\hline Intestinal permeability & $\begin{array}{l}\text { is defined as a functional feature of the intestinal barrier at given sites, measurable by analyzing flux rates across the } \\
\text { intestinal wall as a whole or across wall components of defined molecules that are largely inert during the process and that } \\
\text { can be adequately measured in these settings }\end{array}$ \\
\hline $\begin{array}{l}\text { Normal intestinal } \\
\text { permeability }\end{array}$ & $\begin{array}{l}\text { is defined as a stable permeability found in healthy individuals with no signs of intoxication, inflammation or impaired } \\
\text { intestinal functions }\end{array}$ \\
\hline $\begin{array}{l}\text { Impaired intestinal } \\
\text { permeability }\end{array}$ & $\begin{array}{l}\text { is defined as a disturbed permeability being non-transiently changed compared to the normal permeability leading to a loss } \\
\text { of intestinal homeostasis, functional impairments and disease }\end{array}$ \\
\hline
\end{tabular}




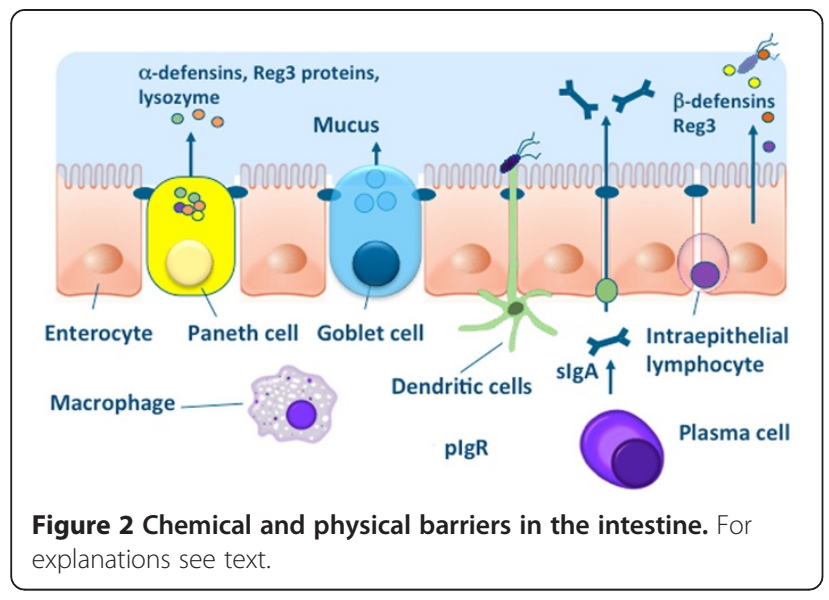

apoptosis and are extruded into the lumen. Intestinal stem cells can differentiate into 4 cell linages, namely enterocytes, enteroendocrine cells, mucus producing goblet cells and Paneth cells which are only found in the human small intestine [26]. Goblet cells secrete mucin which is heavily glycosylated and polymerized into a enormous net-like structure. Mucin 2 is the major component of secreted mucin in the large and small intestine and plays a key role in keeping intestinal microbes at a distance from the epithelial surface.

Colonization by commensal intestinal microbiota is limited to an outer "loose" mucus layer, and interacts with the diverse oligosaccharides of mucin glycoproteins, whereas an "inner" adherent mucus layer is largely devoid of bacteria [27]. In both experimental models of IBD and in humans the mucus layer becomes more permeable to bacteria and is therefore considered critical etiological factors in this disease and possibly other intestinal disorders [28]. In addition to the surface mucins the apical surface of the epithelium is protected by a glycocalyx made up of membrane tethered mucins. These are also glycosylated and are released upon binding by microorganisms as a defense mechanism to prevent colonization [29,30].

It has recently been recognized that sites of cell shedding represent a third site for the physical intestinal barrier. The intestinal epithelium is one of the most dynamic in the body with epithelial cells arising from stem cells at crypt bases, migrating to the villus tip in the case of the small intestine and the colonic surface from where they are shed. This cellular extrusion process could potentially compromise the integrity of the epithelium. Recent studies have shown that under physiological healthy conditions epithelial extrusion is triggered by stretching of the epithelial cell, which is detected by activation of the stretch-sensitive cation channel Piezo [31]. This triggers a signal transduction pathway involving the sphingosine 1 kinase, the S1P receptor and Rho kinase [32]. This pathway triggers by a redistribution of proteins from the tight junction to surround the shedding cell and to fill the gap left after extrusion is completed thereby maintaining the barrier [33]. This mechanism appears to be very robust such that the barrier rarely fails at sites of cell shedding.

Inflammatory cytokines such as TNF $\alpha$ usually increase the rate of cell shedding. Under these circumstances, the redistribution of the tight junction does not always seal the gap left by shedding cells. This is frequently observed because more than one epithelial cell is shed from one site leaving a gap that is too large to be plugged by the redistribution of tight junction proteins [34].

An important point is the direction of flow through gaps that are not sealed can be either into or out of the intestinal wall. Local pressure, electrochemical and osmotic gradients determine the direction of flow. In contrast to the tight junction the defects at cell shedding sites are too wide to permit local inwardly directly osmotic gradients to be generated. Instead the direction of flow is determined by the balance of inwardly directed osmotic and electrochemical gradients between the lumen and the subepithelium and outwardly directed hydrostatic gradients generated by hydrostatic pressure and peristalsis (Figure 3). There is a positive hydrostatic pressure in the subepithelium. The direction of flow is thus highly labile and can be readily changed by alterations of osmolarity of the luminal contents as will occur during the mixing as the food travels down the intestine [35].

The mucus components of the gut barrier are fortified by antimicrobial peptides and proteins including lysozyme. Paneth cells produce a range of antimicrobial factors to protect the crypt cells from infection with microorganisms

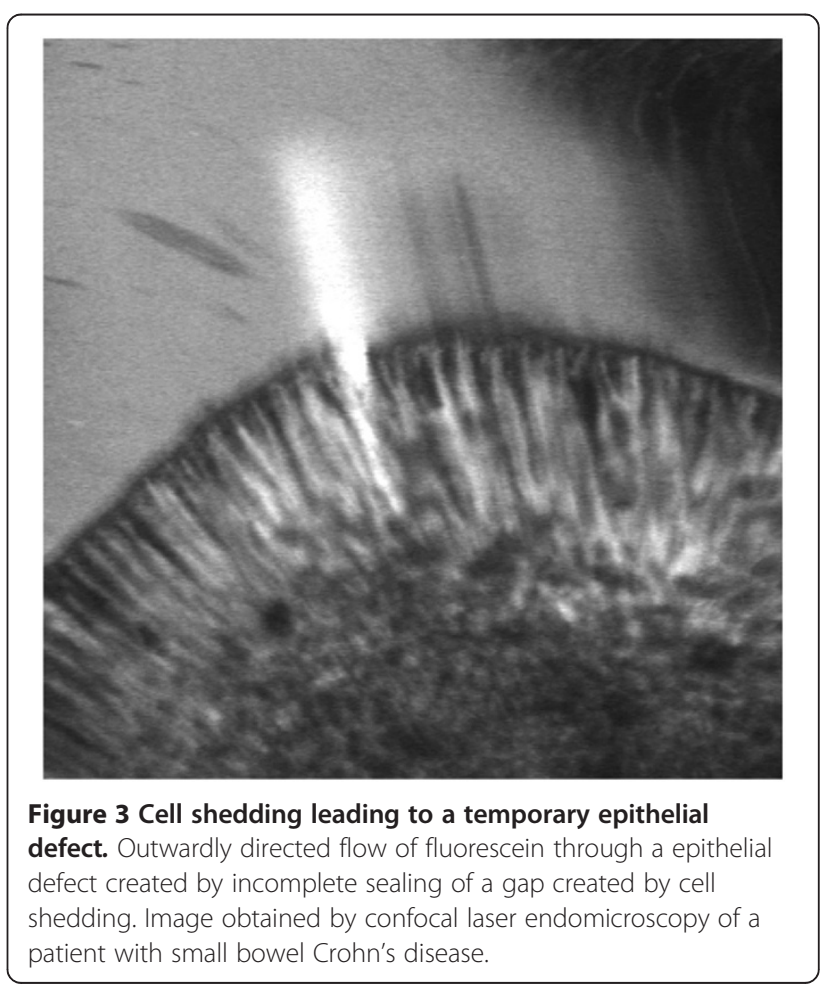


including alpha-defensins, lysozyme and Reg3 proteins [36,37]. Epithelial cells secrete beta-defensins some of which are upregulated in response to sensing of microbes by pattern-recognition receptors such as Toll-like receptors. Ileal CD is associated with a decreased production of Paneth alpha-defensins in response to sensing of microbes by pattern-recognition of commensal bacteria and pathogens, whereas colonic $\mathrm{CD}$ is associated with a reduced expression of HBD1 and a reduced induction of HBD2 and HBD3 also resulting in a reduced mucosal defense [38]. In the mouse, there are more than $20 \alpha$-defensins (cryptidins) produced in Paneth cells, but not in neutrophils, and these are processed differently compared to the human system [39]. The Reg3 proteins have recently been shown to play a key role in barrier defense. For example, mouse Reg3g and HIP/PAP in humans has been reported to be bactericidal for Grampositive bacteria in vitro, and to be important in the spatial compartmentalization of microbes in the intestine [40].

Other structures such as blood vessels, smooth muscle cell layers and components of the enteric nervous system (ENS) contribute to the intestinal barrier by regulating the mucosa and by their capacity to initiate specific defense programs in case of danger $[5,6,18]$.

Mammals produce larger amounts of secretory immunoglobulin A (sIgA) in the mucosa reflecting its central role in immunity and protection against pathogens. B cell activation and proliferation leading to antigen-specific sIgA production occurs in the gut associated lymphoid tissue (GALT) via T cell dependent pathways [41]. In addition to the $\mathrm{T}$ cell-dependent pathway for IgA production, there is a faster mechanism for generating IgA responses to highly conserved antigenic determinants on commensal bacteria and pathogens $[42,43]$. In mice, this involves a specialized subset of B-1 cells that can rapidly produce secretory IgA in the absence of help from CD4+ T cells [44]. This SIgA commonly known as 'natural' antibody and appears to be bind several antigens. The repertoire of 'natural IgA' is restricted and affinity maturation is limited, although the heavy-chain variable region genes used by IgA-producing plasma cells in the gut are somatically hyper-mutated, to diversify antibody specificity [42]. Equivalent B-1 cells have not been identified in humans but they may have functionally equivalent cells that can colonize the lymphoid tissues and generate natural antibody [45].

Much of the IgA produced in the gut appears not to be reactive to the commensal microbiota. Nevertheless, in germ-free mice sIgA is present at very low levels in the gut and increases substantially soon after colonization with bacteria [46]. sIgA can mediate protection at mucosal surfaces by binding to viruses and bacteria to prevent or inhibit their attachment to and/or invasion of epithelial cells, a process known as immune exclusion [47]. Additionally, sIgA can also interact with antigens presented by intracellular pathogens in endosomes during the pIgR-mediated transport through epithelial cells. Recently we have begun to appreciate its homeostatic roles of SIgA in shaping the intestinal microbiota, preventing mucosal inflammation by immune exclusion, removal of antigen-antibody complexes in the LP and the neutralization of inflammatory mediators.

\section{Serotonin, histamine and proteases}

Serotonin/5-hydroxytryptamin (5-HT) produced by enterochromaffin cells in the intestine and histamine produced by mucosal mast cells acts as a proinflammatory mediators in the intestine and modulate intestinal permeability [48-51]. Our experiments in serotonin reuptake transporter (SERT) knockout mice revealed that absence of SERT aggravates inflammation, because mucosal 5-HT levels increase in an uncontrolled manner. Interestingly, not only experimental colitis is worsened in SERT-knockout mice compared to normal littermates, but also fructose-induced endotoxin translocation and subsequent steatosis in the liver [50].

\section{Endogenous cannabinoid system}

The plant Cannabis sativa has bee used to treat various disorders of the gastrointestinal tract such as vomiting, anorexia, diarrhea, and intestinal inflammation [52]. Recent experimental data in animals indicate now that the intestinal barrier function is regulated in vivo through activation of the intestinal cannabinoid type 1 receptor (CB1R). CB1R, but not CB2R, exerts a protective role in colonic permeability as shown in CB1R knockout mice that respond to stress with enhanced permeability compared to normal littermates [53]. Most interestingly, the gut microbiota - and possibly also nutrients - contribute to the regulation of the intestinal barrier via setting the tone of intestinal endocannabinoid system. Cani et al. reported that in obese mice, CB1R is upregulated, and treatment with a CB1R antagonist results in reduced translocation of bacterial antigens such as lipopolysaccharide (LPS) into the systemic circulation [54]. The opposing effects of cannabinoids (either improving or worsening intestinal permeability) might be related to the recent observation that endocannabinoids such as anandamide worsen permeability while phytocannabinoids like cannabidiol and tetrahydrocannabidiol, which might act as (partial) CB1R antagonists, promote protection or recovery from intestinal permeability [52].

\section{Regulation of intestinal permeability by diet and bacteria Intestinal barrier and the microbiota}

The intestinal tract harbors the largest bacterial community associated with the human body, reaching densities of about $10^{12}$ bacteria per gram of luminal content in the distal colon. Each individual carries up to a few hundred species of intestinal bacteria most of which fall into two dominant phylum, Bacteroidetes and Firmicutes [55-57]. The predominance of certain cornerstone species in the microbiota has been proposed to drive one of three preferred ecological compositions 
known as enterotypes [58]. Enterotypes appear to be independent of individual host characteristics such as body mass index, age, or gender or geographical location but may be influenced by diet and host genetic backgrounds [59].

The intestinal microbiota is considered to be largely symbiotic in nature and involved in various processes, including the breakdown and absorption of nutrients, the production of vitamins and hormones, and the prevention of colonization by pathogens (Table 2). The gut barrier plays a key role in the avoidance of inflammatory responses to the microbiota and is regulated by a finely tuned network of immune mechanisms for microbial recognition and tolerance to the microbiota $[60,61]$. Failure to achieve or maintain this equilibrium between a host and its microbiota has negative consequences for both intestinal and systemic health. Several diseases have been linked to changes in the microbiota populations, or to reduction of the microbiota's diversity, including, atopic diseases, inflammatory bowel disease (IBD), diabetes, obesity, cancer and very recently, even neuropathologies. Some of these pathologies are associated with altered barrier function and increased permeability of the epithelium [6,7]. The microbiota is implicated in these physiological changes for example via reduced numbers of butyrate producers and butyrate production $[62,63]$, thereby contributing to the pathophysiology of inflammatory diseases [64]. In IBD, inflammation is also linked to increased abundance of pathobionts such as adherent invasive $E$. coli (AIEC), which can directly damage the barrier to promote inflammatory responses $[65,66]$.

Mucus may serve as binding sites for bacteria enabling them to persist and colonize the surface of the mucus layer. Several species from different phyla can grow on mucus as a carbon source although complete degradation of mucus depends on the concerted action of a consortium of bacteria, due to the high degree of diversity of the mucin oligosaccharide chains and their possible modifications. The normal intestinal microbiota triggers the epithelium for synthesizing mucus sugars, while selected commensal bacteria such as Akkermansia muciniphila regulate mucus layers by utilizing mucins as an energy source $[67,68]$. When microbiota are not present to degrade mucus e.g. in germ-free rodents, mucus production and degradation are imbalanced, leading to a doubling in the thickness of the mucus layer and swelling of the cecum due to the accumulation of mucus, and the resulting retention of water [69]. Mucin degradation has been associated with bacterial pathogenicity as it erodes the protective mucus layer but in relation to the microbiota it might serve as a host 'prebiotic'

Table 2 Proposed functions of the human intestinal microbiota

I Host defense against pathogens and toxins

II Development and maintenance of the intestinal immune system

III Support of digestion by supply of enzymatic capacity to stimulate growth of symbionts and shape the ecology of the microbiota.

\section{The intestinal barrier and bacterial pathogens}

Many pathogens specifically interact with defined element of the intestinal barrier underlining the importance of bacterial-host interactions in both health and disease. For example, epithelial tight junctions (TJ) can be altered by several pathogens (Table 3 ). These effects may result from direct modification of $\mathrm{TJ}$ proteins such as occludin, or by different kinase mediated effects on the perijunctional actomyosin ring [70-85]. Pathogens, as well as usage of antibiotics, might disturb the intestinal mucus layer, either by enhancing mucus degradation, or by inhibiting the normal commensal triggers for mucus production [86].

\section{Regulation of gut permeability by diet, prebiotics and probiotics}

Since we now know about the clinical implications, interest in understanding the regulation of this barrier is growing. Two major regulatory factors could be identified, diet/nutrients/prebiotics, and, secondly, the intestinal microbiota/probiotics. Both are related to life style, which suggests that environmental factors might influence the function of the intestinal barrier and thus gut health [6]. The molecular mechanisms that regulate the epithelial tight junction and the paracellular pathway in response to luminal nutrients as D-glucose are less well defined but have been proposed to involve the cytoskeleton including myosin light chain phosphorylation [87].

The effect of diet on intestinal permeability is dependent on individual factors such as the host's genetic susceptibility, and also on the intestinal microbiota. For example, the increased gut permeability during metabolic adaptation to high fat diet (HFD) is associated to altered gut microbiota [13]. Dietetic factors that promote increased intestinal permeability and subsequent translocation of bacteria resulting in inflammatory reactions in the liver, the white adipose tissue, the brain, and other organs trigger metabolic diseases such as insulin resistance. This pathophysiological cascade is now accepted to be of major relevance for the development of metabolic diseases including type II diabetes, cardiovascular diseases and non-alcoholic fatty liver disease (NAFLD) or non-alcoholic steatohepatitis (NASH) [88-93]. Therefore it is tempting to speculate that tools allowing a safe modulation of the intestinal microbiota such as prebiotic food components or probiotic bacteria might be of great interest for future therapy of intestinal barrier-related diseases.

\section{Vitamins}

Vitamin A and its derivatives have been shown to regulate the growth and differentiation of intestinal cells, whereas vitamin A deficiency is associated with increased susceptibility to infection in both human and animal models [1]. 
Table 3 Pathogen interactions with epithelial tight junctions

\begin{tabular}{|c|c|c|c|c|}
\hline Bacteria & Bacterial factors & Mechanism of TJ disruption & Host targets & References \\
\hline \multirow[t]{3}{*}{ H. pylori } & CagA & Cdx2-mediated increase in claudin 2 expression & PAR1 & {$[64-66]$} \\
\hline & Urease & $\begin{array}{l}\text { Phosphorylation of myosin light chain kinase } \\
\text { and occludin internalization }\end{array}$ & MLCK, ROCK & [67] \\
\hline & Unknown & Rho kinase (ROCK)-dependent loss of TJ claudin-4 & IL-1R1, ROCK & [68] \\
\hline \multirow[t]{3}{*}{ EPEC } & Map & Cdc42-dependent filopodia and pedestal formation & Cdc42 & [69] \\
\hline & EspM & Activation of RhoA and TJ disruption & RhoA & {$[70-72]$} \\
\hline & NleA & $\begin{array}{l}\text { Inhibition of host cell protein trafficking through } \\
\text { COPII-dependent pathways }\end{array}$ & COPII & [73] \\
\hline V. parahemo- lyticus & T3SS effectors & Alteration of actomycin ring and TJ disruption & Rho GTPase & {$[74,75]$} \\
\hline $\begin{array}{l}\text { Salmonella enterica } \\
\text { serovar typhimur. }\end{array}$ & $\begin{array}{l}\text { T3SS effectors SipA, } \\
\text { SopB, SopE, SopE2 }\end{array}$ & $\begin{array}{l}\text { Filopodia formation and alteration of } \\
\text { actomycin ring }\end{array}$ & Rho GTPase & [76] \\
\hline Clostridium difficile & enterotoxin $\mathrm{A}$ and $\mathrm{B}$ & $\begin{array}{l}\text { Inactivation of Rho family proteins causing } \\
\text { degradation of filamentous actin }\end{array}$ & Rho and Cdc & [77] \\
\hline Bacteroides fragilis & Enterotoxin or fragilysin & $\begin{array}{l}\text { Toxin degradation of E- cadherin and alteration } \\
\text { of actomycin ring }\end{array}$ & E-cadherin & [78] \\
\hline Vibrio cholera & HA protease & $\begin{array}{l}\text { HA induced cleavage of occludin, alteration } \\
\text { of ZO- } 1 \text { and rearrangement of actin }\end{array}$ & Occludin & [79] \\
\hline
\end{tabular}

Abbreviations: $T$ J tight junctions, PAR1 phytochrome rapidly regulated 1 gene, $M L C K$ myosin light chain kinase, ROCK Rho-associated, coiled-coil containing protein kinase 1, IL-1R1 interleukin 1 receptor, type I, Cdc42 cell division cycle 42, RhoA ras homolog family member A, COPII Rho GTPase, EPEC enteropathogenic Escherichia coli. Other explanations see text.

Vitamin A-deficient diet causes within a few weeks alterations within the commensal bacteria, and impairs the intestinal barrier by changing mucin dynamics and expression of defense molecules such as MUC2 and defensin 6 [94]. Vitamin A deficiency is associated with a decreased small bowel villus height and a reduced disaccharides activity leading to more severe intestinal injury in experimental enteritis [95]. Cross-sectional investigations of children with high rates of subclinical vitamin A deficiency showed that serum retinol concentrations are inversely correlated with intestinal permeability [96]. Apart from vitamin A, also vitamin $\mathrm{D}$ seems to play a role for the intestinal barrier. Vitamin D deficiency, a characteristic of IBD, is correlated with the severity of disease [97]. Experiments in vitamin D receptor knockout mice showed that vitamin D deficiency might compromise the mucosal barrier, leading to an increased susceptibility to mucosal damage and an increased risk of IBD [98].

\section{Short chain fatty acids (SCFA)}

These organic acids comprising acetate, propionate, butyrate and valerate are produced by intestinal microbial fermentation of undigested dietary carbohydrates in the colon. Among them, butyrate plays a particular role for maintaining the intestinal barrier, as shown in IBD, in which deficit in butyrate causes tight junction lesions and finally impaired intestinal permeability [99]. In turn, experiments in a rat model of DSS-induced colitis showed that treatment with butyrate leads to a recovery in transepithelial resistance, which was associated with maintenance of tight junction integrity and inhibition of TNFo release [100].

\section{Prebiotics}

Apart from the effects of fermentation products of prebiotics such as SCFA, prebiotics by itself might have stabilizing effects on the intestinal barrier. Indeed, prebiotic galactooligosaccharide (GOS) protects against salmonella infections and against barrier impairment in experimental pancreatitis [101,102]. Most recently, the group of Cani and Delzenne showed that prebiotic fructo-oligosaccharides (FOS) attenuate experimental hepatic steatosis, possibly by modulating the intestinal microbiota or the intestinal barrier function or both [103].

\section{Western style diet}

A number of animal studies investigated effects of high-fat diets on the composition of gut microbiota and on intestinal permeability $[9,13]$. Consistently, energy-rich high-fat diets enhanced intestinal permeability resulting in metabolic endotoxinemia. The Western style diet, which is characterized by a high amount of fat and carbohydrates, induced similar or even more pronounced changes [10]. Moreover, our studies revealed that among dietary sugars fructose plays a particular role with regard to the intestinal barrier. Using TLR-4 mutant mice we showed that the onset of fructose-induced NAFLD is associated with intestinal bacterial overgrowth and increased intestinal permeability, subsequently leading to an endotoxin-dependent activation of hepatic Kupffer cells [104]. Recently, we could also show in a mouse-feeding model that chronic consumption of 30\% fructose solution for eight weeks was associated with the loss of the tight junction proteins occludin and 
ZO-1 in the duodenum and a subsequent increase of bacterial endotoxin in the portal vein [105]. Apart from vitamins and fatty acids, other dietetic factors have been examined such as plant-derived flavonoids, e.g. quercetin present in grapes and onions, which increased epithelial resistance and claudin-4 expression in epithelial cells [106,107].

\section{Probiotics}

Several studies report the use of commensal bacteria and probiotics to promote intestinal barrier integrity in vivo [108-111] although some studies have been negative or inconclusive. Many studies report enhancement of the intestinal barrier in vitro or protection from barrier disruption by probiotics. For example, the probiotic E.coli Nissle 1917 (EcN) was shown to prevent barrier disruption caused by infection of T84 and Caco- 2 cells with an enteropathogenic E. coli strain [112]. The addition of EcN alone increased expression of $\mathrm{ZO}-2$ protein and redistribution of ZO-2 from the cytosol to cell boundaries in vitro [112]. EcN also increases claudin-14 expression in the epithelial TJ and its effect is mediated via TcpC via PKC-zeta and the MAPK ERK1/2. A similar effect was observed in intestinal epithelial cells isolated from germfree mice treated with $\mathrm{EcN}$ [113]. Metabolites secreted by Bifidobacterium infantis $Y 1$, one of the components of the probiotic product VSL\#3, leads to an increase in expression of ZO-1 and occludin while reducing expression of claudin-2 leading to enhanced effects on transepithelial resistance and altered ion secretion [114]. Another probiotic strain Lactobacillus plantarum MB452 (from the VSL3 probiotic) was shown to induce transcription of occludin and cingulin genes [115].

Enteric pathogens often gain access to the body by altering the structure and function of tight junctions to increase permeability of the barrier via the secretion of proteases, which can cleave tight junction proteins or by altering the cytoskeleton [116]. Inflammatory cytokines such as TNF $\alpha$ and IFN $\gamma$, which are induced during infection and in IBD, have been shown to increase intestinal permeability in general, although single inflammatory models yielded different results [114] while probiotics and commensals can reverse such inflammatory dysfunctions in human intestinal epithelial cells, e.g. by improving barrier functions or by inhibition of pathogen adherence [115,117-120]. Also synergistic effects between sIgA and probiotics have been described [121].

Importantly, one study has shown that L. plantarum can regulate human epithelial TJ proteins in vivo and to confer protective effects against chemically induced disruption of the epithelial barrier in an in vitro model [122]. Administration of L. plantarum into the duodenum of healthy human volunteers was shown to significantly increase ZO-1 and occludin in the vicinity of TJ structures [122]. These results suggest that administration of $L$. plantarum can enhance the stability of $\mathrm{TJ}$ complexes in humans and may attenuate their disruption by cytokines, toxins and pathogens. Apart from L. plantarum, other probiotic Lactobacillus strains seem to have protective effects on the intestinal barrier using different in vitro settings or mouse models of disease, namely $L$. salivarius strains UCC118 and CCUG38008, L. rhamnosus GG, Lactobacillus casei strain DN-114 001, and L. casei strain Shirota [123-127]. Also the probiotic E. coli Nissle 1917 up-regulates tight junction proteins such as claudin 14 expression and other components of the intestinal barrier $[112,113,128]$.

In summary, imbalances in the composition of bacterial community in the intestine can lead to transient intestinal dysfunctions, barrier modulation, and chronic disease states such as IBD. Understanding how this ecosystem is regulated, e.g. by diet and other exogenous factors, and how to manipulate it is thus essential for disease prevention and therapy.

\section{Measurement of intestinal permeability}

Intestinal permeability and integrity can be measured in many ways. The techniques used for permeability and integrity assessment vary depending on the setting (in vitro versus in vivo measurements), the species (human or animal models), the marker molecules used for assessment (ions, carbohydrates of different sizes, macromolecules and antigens, bacterial products and bacteria), and the compartments used for measurement of the marker molecules (peripheral blood, portal vein blood, urine). If one focuses just on the epithelial barrier, the flux of molecules is very much dependent on the type of molecules and the type of defects, as illustrated in Figure 4. To measure such dysfunctions, the Ussing chamber is widely used, both for human and animal studies. This ex vivo approach to measure intestinal permeability requires intestinal tissue specimens, either biopsies or surgical specimens.

In vivo assessment of intestinal barrier function and permeability in humans is currently possible by using intestinal permeability assays, and by the assessment of biomarkers of epithelial integrity such as soluble adhesion molecules, other biomarkers of immunity or inflammation, or bacterial

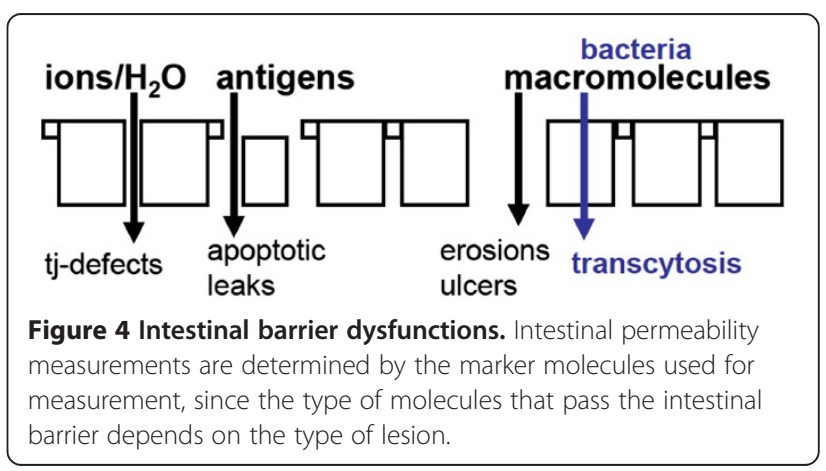


markers like circulating endotoxin (Tables 4 and 5). In addition, histological approaches and scanning electron microscopy analyses have been used in experimental settings. The most relevant methods for assessment of intestinal barrier function and permeability in clinical settings are described in more detail in this chapter.

\section{The Ussing chamber}

The Ussing chamber allows the measurement of shortcircuit current as an indicator of active ion transport taking place across the intestinal epithelium. Basically, the chamber consists of two halves that are mounted together containing the tissue specimen with the apical side isolated from the basolateral side. The two half chambers are filled with equal amounts of Ringer solution (Figure 5). The active ion transport produces a potential difference across the epithelium $\left(V_{E P}\right)$. The voltage difference generated is measured using two voltage electrodes that are placed as near as possible to the tissue/epithelium. The spontaneous voltage is cancelled out by injecting a counter current using another two current electrodes that are placed far away from the epithelium. This current externally injected is called short-circuit current (Isc) and is the exact measure of net ion transport taking place across the epithelium. The transport of ions through the epithelium, in particular the secretion of chloride, plays an important role in the gut, and is paralleled by water transport $[15,129]$.

Recent studies showed that luminal factors such as nutrients, bacteria, and bacterial products including probiotics can restore intestinal permeability previously impaired by infections or chronic inflammation, as assessed in the Ussing chamber $[16,130,131]$. In addition, also glutamine is an important luminal component thought to preserve intestinal barrier function, although the molecular mechanism beyond its role as a metabolic fuel is not yet established [132]. Most importantly, malnutrition is associated with increased intestinal permeability, as shown in liver cirrhosis patients, suggesting that nutrients are needed to maintain normal barrier function in the intestine [133]. The Ussing chamber technique is well established since many years and has been successfully used for both human and animal studies. Limitations of Ussing chamber measurements are the invasiveness because of the need for fresh intestinal tissue, and the lack of correlations between Ussing chamber data and other permeability assays raising the question of which aspects of the intestinal barrier can be assessed by this approach.

\section{Permeability assays}

Permeability assays usually use oligosaccharides of large size, e.g. lactulose or high MW-PEGs of 1500 or $4000 \mathrm{kD}$, and sugars of small size, e.g. mannitol, L-rhamnose, or low MW-PEG of $400 \mathrm{kD}$, or other indigestible probes such as 51Cr-EDTA that are administered orally. The large size molecule is thought to cross the paracellular intestinal pathway only if the intestinal barrier function is compromised. In case of barrier function loss such probes cross the intestinal barrier, appear into the circulation and

Table 4 Means for the assessment of intestinal permeability (functional tests, bacteria-related tests)

\begin{tabular}{|c|c|c|c|c|c|c|}
\hline Means & $\mathrm{Hu}$ & $A n$ & Test molecules & Test site & Material needed & Disadvantages \\
\hline \multicolumn{7}{|l|}{ Ex vivo } \\
\hline Ussing chamber & $x$ & $x$ & $\mathrm{H}_{2} \mathrm{O}$, ions, sugars etc., & site specific & biopsies & invasive \\
\hline \multicolumn{7}{|c|}{ In vivo - permeability assays } \\
\hline Lactulose/mannitol & $x$ & $x$ & oligosaccharides of different MW & small intestine & urine & time consuming \\
\hline Sucralose & $x$ & $(x)$ & sucralose(comb.)* & colon & urine & time consuming \\
\hline Sucrose & $x$ & $(x)$ & sucrose $(\text { comb.) })^{*}$ & stomach & urine & time consuming \\
\hline PEG4000/400 & $x$ & $(x)$ & polyethylene glycols & whole intestine & urine & time consuming \\
\hline 51Cr-EDTA & $x$ & $x$ & 51Cr-EDTA & whole intestine & urine & radio-activity \\
\hline \multicolumn{7}{|c|}{ In vivo - bacteria-related } \\
\hline LAL assay & $x$ & $x$ & endotoxin (LPS) & whole intestine & plasma & assay limitation \\
\hline EndoCAb & $x$ & $x$ & anti-LPS antibodies & whole intestine & serum & only in acute phase \\
\hline D-lactate & $x$ & $x$ & bacterial lactate & whole intestine & plasma & low specificity \\
\hline Butyrate production & $x$ & $x$ & $\mathrm{BPB}(\mathrm{PCR})$ & colon & feces & special labs, limited data \\
\hline Hemolysin test & $x$ & $x$ & pathogens (cell culture) & colon & feces & special labs, limited data \\
\hline Inner colon mucus & $x$ & $x$ & quantification of bacteria & colon & biopsies & invasive,limited standardization \\
\hline Liver steatosis & $x$ & $x$ & fat content in the liver & whole intestine & MRT, US & expensive unspecific \\
\hline Breath tests & $x$ & $x$ & fat content in the liver & whole intestine & GC/MS & unclear specificity \\
\hline
\end{tabular}

Abbreviations: Hu suitable for the human system, An suitable for animal models, 51Cr-EDTA chromium labeled EDTA, BPB butyrate-producing bacteria, EndoCAb circulating endotoxin core antibodies, GC gas chromatography, LAL limulus amebocyte lysate assay, LPS lipopolysaccharide, MRT magnetic resonance tomography, MS mass spectroscopy, PEG polyethylene glycols, US ultrasound. *in combination with Lactulose/mannitol test. 
Table 5 Means for the assessment of intestinal permeability (biomarkers, histology)

\begin{tabular}{|c|c|c|c|c|c|c|}
\hline Means & $\mathrm{Hu}$ & $A n$ & Test molecules & Test site & Material needed & Disadvantages \\
\hline \multicolumn{7}{|c|}{ In vivo - biomarkers of epithelial cell damage } \\
\hline Citrulline & $x$ & $x$ & endogenous ep product & small intestine & plasma & \\
\hline FABP & $x$ & $x$ & endogenous ep marker & site- specific & plasma & only in acute phase? \\
\hline aGST & $x$ & $x$ & endogenous ep enzyme & n.a. & plasma, urine & only in acute phase? \\
\hline Claudin-3 & $x$ & $x$ & ep tight junction protein & n.a. & urine & limited data \\
\hline \multicolumn{7}{|l|}{ In vivo - other biomarkers } \\
\hline Fecal calprotectin & $x$ & $(\mathrm{x})$ & neutrophil release product & colon & feces & unspecific marker of gut inflammation \\
\hline a1-anti- trypsin test & $x$ & $(\mathrm{x})$ & endogenous amino acid & small intestine & feces/ serum & unclear specificity \\
\hline $\operatorname{slg} A$ & $x$ & $x$ & $\lg A(E L I S A)$ & whole intestine & serum & low specificity \\
\hline \multicolumn{7}{|c|}{ In vivo - histological approaches } \\
\hline Tight junction expression & $x$ & $x$ & RNA (qPCR), Western blot & site- specific & biopsies & invasive \\
\hline Goblet cell analysis & $x$ & $x$ & histology & site- specific & biopsies & invasive \\
\hline Shedding of epithelium & $x$ & $x$ & histology & site- specific & biopsies & invasive \\
\hline Paneth cell loss ${ }^{* *}$ & $x$ & $x$ & histology & site- specific & biopsies & invasive \\
\hline Defensins & & & RNA (qPCR), Western blot & site- specific & biopsies & invasive \\
\hline Mucus analysis*** & & & histology/ staining & site- specific & biopsies & invasive \\
\hline
\end{tabular}

Abbreviations: aGST a-glutathione S-transferase, ep epithelial, FABP fatty acid binding protein, n.a. not applicable, $q P C R$ qunatitative PCR, see also Abbreviations in Table 4. ${ }^{* *}$ Ref. Nr. 226; ${ }^{* * *}$ Ref. Nr. 227.

can be detected in urine after renal excretion. The small size molecule is thought to traverse the intestinal barrier freely, independent of barrier function loss, and is affected in the same way as the large molecular probe by the preand postmucosal confounders like as gastric dilution, gastrointestinal motility, bacterial degradation, and renal function. Therefore, the ratio of the urinary concentration of both molecules measured after 5-6 h would more accurately reflect the paracellular passage across the intestinal barrier than isolated measurement of urinary oligosaccharides. The "active" test results depend on the test probe size, the way of absorption (passive or active transport in the intestine), the site and velocity of absorption, and the kinetics

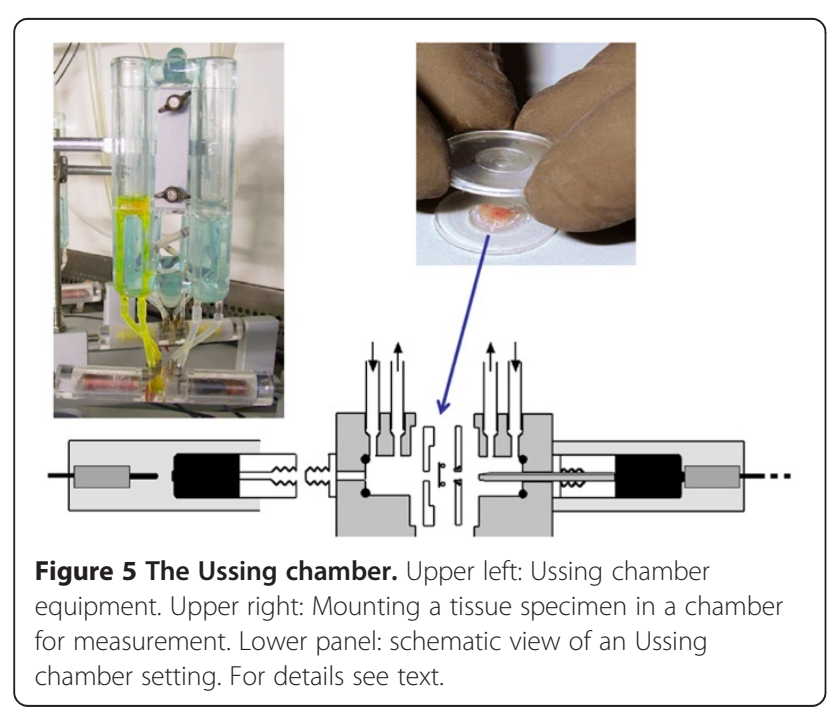

of distribution into different body compartments. Alternatively to this "active" assessment of the barrier, "passive" assessment of the barrier is possible by the quantification of luminal compounds such as endotoxins and bacterial fermentation in plasma as markers for barrier function integrity. The advantage of this approach is that no timeconsuming urine collection is needed. On the other hand, the substances are not always easily measured because of technical limitations (e.g. endotoxin assays) or hepatic metabolism $[17,134]$.

Laboratory analysis of urine samples is usually performed using high pressure liquid chromatography (HPLC) or liquid chromatography in combination with mass spectrometry (LC/MS). Since some of the saccharides, as lactulose, can cause increased intestinal motility, the administered dose should be kept as low as possible. Permeability assays are usually useful only for assessing small intestinal permeability, since lactulose is degraded by bacteria in the large intestine. To evaluate whole intestinal permeability, nondegradable probes such as sucralose or erythritol, which remain unaffected by bacteria in the colon, are added to classical DST, resulting in the so-called triple sugar test. The lactulose excretion over $24 \mathrm{~h}$ (likely to represent only small intestinal permeability), subtracted from 24-h sucralose excretion, is considered to give an isolated measure of colonic permeability [134]. Other studies focused on measurement of gastroduodenal permeability, have used sucrose or glucose as test substances. Sucrose is rapidly degraded by sucrase, an enzyme secreted in large amounts by mature enterocytes in the duodenum. Therefore, enhanced plasma or urinary levels of sucrose are thought to reflect only 
permeability of the stomach and proximal duodenum [135]. Glucose is even independent of sucrose digestion. Most recently, both approaches have been combined to assess intestinal permeability at different sites. The "multi sugar test" is based on administration of sucrose, lactulose, sucralose, erythritol, and rhamnose simultaneously in order to assess gastro-duodenal, small intestinal and large intestinal permeability in humans [136].

Increased permeability for saccharides has been reported in patients with CD $[137,138]$, celiac disease [139], adverse reaction to food $[140,141]$, and in critically ill patients or patients undergoing major surgery $[142,143]$. In contrast to lactulose and mannitol, PEGs have the advantage of being inert and can therefore be used to measure both small and large intestinal permeability. They have been used successfully to assess permeability changes in patients with irritable bowel syndrome [144], pancreatitis [145], liver cirrhosis [146], and intestinal ischemia reperfusion injury [147]. Some studies have reported increased colorectal permeability for $51 \mathrm{Cr}$-EDTA in patients with IBD [148]. However, the tests have never gained a place in everyday practice for diagnosis and follow up of such patients groups, mainly because the test is impractical in use and detection methods are complex and not widely available.

Some studies, however, have shown that such permeability assays in intensive care patients have pitfalls. Firstly, decreased motility and altered clearance of the different sugars as a result of renal dysfunction is a complicating factor in these patients. Secondly, the use of mannitol appeared to be unsuitable in patients receiving red blood cell transfusion, since mannitol is used in the storage solution of bank blood [17].

\section{Bacteria-related markers}

LPS measurement Despite well-known technical limitations of the assay, resulting from the low levels detectable in peripheral blood, several studies have successfully used LPS assays to show endotoxemia, mostly in patients with sepsis [149]. Enhanced levels of LPS were found also in patients with obesity and metabolic syndrome [150,151], which might indicate bacterial translocation from the gut lumen to the circulation as a consequence of intestinal barrier function failure. While LPS can be quite easily measured in portal vein blood in animals, it remains a challenge to measure LPS in peripheral blood in humans and it requires careful standardization of the measurement.

\section{Circulating endotoxin core antibodies (EndoCAb)} Alternatively to the measurement of endotoxin, which yields best results if measured in portal vein plasma, measurement of circulating EndoCAb allowing the quantification of immunoglobulins (IgG, IgM and $\operatorname{IgA}$ ) against the inner core of endotoxin have been proposed for the acute phase of intestinal barrier damage. This inner core consists of a hydrophobic part, lipid A, which is attached to a core oligosaccharide. Lipid A is highly conserved across the whole range of Gram-negative microbiota. Moreover, it is this part that is considered responsible for endotoxin toxicity. Several studies showed decreased EndoCAb levels postoperatively, accounting for the degree of exposure to endotoxin $[152,153]$. Thus, consumption of these circulating immunoglobulins following translocation of gutderived endotoxins can be used to acquire indirect information on the intestinal epithelial barrier function. The approach is so far limited by the fact that it has been performed successfully only in postoperative patients but not in patients with chronic diseases.

Plasma D-lactate level have been originally proposed as a marker for diagnosis of bacterial infections, since D-lactate is a fermentation product produced by many bacteria including those present in the human gastrointestinal tract. Low circulating levels of D-lactate are found in healthy individuals, but in case of intestinal barrier function loss, these levels will rise as a consequence of increased translocation across the intestinal mucosa. Various studies proposed a relationship between plasma D-lactate and intestinal permeability, e.g. in patients undergoing open aortic surgery and ischemic colonic injury. However, results should however be interpreted cautiously where there is bacterial overgrowth since the augmented presence of bacteria could result in increased fermentation of undigested carbohydrates to D-lactate. Therefore, the usefulness of plasma D-lactate as marker for colonic barrier function in man is a subject for future research [17].

Fecal butyrate concentrations Generation of SCFA such as butyrate depends on prebiotic and other dietetic factors as well as on the composition and activity oft he intestinal microbiota. It has been shown that butyrate decreases bacterial translocation in cells models [154] and modifies the expression of the tight junction proteins claudin-1 and claudin- 2 in favor of a barrier preservation $[99,155]$. Therefore, butyrate deficiency can be taken as an indirect indicator of impaired intestinal barrier function.

Bacteria-derived hemolysin is a pro-inflammatory toxin that can impair the intestinal barrier. Conditions leading to enhanced hemolysin concentrations in the intestine will enhance intestinal permeability [156]. However, butyrate and hemolysin assays are poorly established for permeability assessment so far.

Assessment of fatty liver disease Translocation of bacterial or bacterial products such as LPS from the intestine to the liver has been proposed as trigger for liver inflammation and fatty liver disease [151]. We could show that LPS translocation indeed induces hepatic steatosis in mice suggesting 
that enhanced intestinal permeability is associated with fatty liver disease assessed by histological examination, magnetic resonance tomography or sonography [104]. Alternatively, fatty liver disease can be assessed by a combination of three volatile bacterial compounds exhaled by a breath test and analyzed by gas chromatography-mass spectrometry [157]. It has to be considered that LPS is likely not the only mechanisms that might cause fatty liver disease, limiting the specificity of this approach.

\section{Analysis of intestinal mucus for bacterial content} Most recently, it has been shown that under conditions characterized by an impaired intestinal barrier, luminal bacteria enter the inner colon mucus normally impenetrable for the commensals [28]. Therefore, measurement of bacteria in the inner colon mucus of biopsies could serve as a novel marker of intestinal barrier function and permeability. However, a better standardization of this analysis is wanted to establish it as a novel permeability assay.

The bacteria-related markers are clearly less established as markers for intestinal permeability in humans compared to the classical permeability assays; however, the fact that they likely reflect different characteristics of the intestinal barrier, is of great interest and might become of more relevance in future.

\section{Biomarkers of epithelial cell integrity}

Plasma levels of citrulline, an amino acid not incorporated into proteins, but produced by small intestinal enterocytes from glutamine have been proposed as a marker of functional enterocyte mass. Loss of small bowel epithelial cell mass results in impaired intestinal permeability and in declined circulating levels of citrulline, as is shown in haemopoietic stem cell transplant recipients suffering from severe oral and gastrointestinal mucositis following intensive myeloablative therapy [158]. More recently, citrulline was established as a valuable marker for chemotherapy-induced mucosal barrier injury in pediatric patients [159]. Most interestingly, sensitivity and specificity seem to be better for the citrulline assay compared with sugar permeability tests [160].

Fatty acid binding proteins (FABP) are small (14-15 kDa) cytosolic water-soluble proteins, present in mature enterocytes of the small and large intestine. Their function is the transport of fatty acids from the apical membrane of the enterocyte to the endoplasmic reticulum where biosynthesis of complex lipids occurs. Three types of FABP are present in the gut; intestinal FABP (I-FABP) found predominantly in the jejunum - less in the colon, liver FABP (L-FABP) found in liver, kidney and intestine, and ileal bile acid binding protein (I-BABP) exclusively present in the ileum. FABP can be measured sensitively in both plasma and urine using an enzyme-linked immunosorbent assay (ELISA). Basal levels of FABP have been reported to reflect the physiological turnover rate of enterocytes, whereas elevated levels indicate intestinal epithelial cell damage. Elevated circulating or urinary FABP levels were reported in patients with intestinal ischemia, systemic inflammatory response syndrome (SIRS) and necrotizing enterocolitis [161-163]. Moreover, FABPs have been established as markers of the intestinal barrier function with prognostic relevance in patients with liver transplantation [164], and for disease activity in celiac disease [165,166]. Since FABP are differentially expressed along the intestinal tract, measurement of specific FABP could be a promising tool to provide information on disease localization [17]. However, data are limited for changes in chronic diseases such as IBD or metabolic disorders.

Glutathione S-transferases (GSTS) are involved in cell protection, antioxidation and detoxification of toxic and foreign compounds within the cell by conjugating them to glutathione. The GST family consists of four subgroups displaying tissue variation; $\alpha$ GST, $\mu$ GST, $\pi$ GST and $\theta$ GST. Whilst $\mu$ GST, $\pi$ GST and $\theta$ GST are present in cells of various organs, $\alpha \mathrm{GST}$ is predominantly present in liver, kidney and intestine and has been proposed as a potential marker for, amongst others, intestinal epithelial cell damage [17]. Several studies reported that mesenteric ischemia could reliably be predicted by plasma $\alpha$ GST levels in patients suspected for acute mesenteric ischemia $[167,168]$. However, increased plasma or urine levels of aGST can indicate intestinal damage as well as liver and kidney damage, because $\alpha$ GST is expressed in epithelial cells of all these organs. Therefore, this test might be useful for assessment of intestinal damage when isolated intestinal damage is suspected.

Tight junction (TJ) status can be assessed as a marker for paracellular barrier integrity loss. In particular, claudins are transmembrane epithelial proteins being mainly responsible for intestinal barrier function. The group of Schulzke an co-workers showed a disturbance of the barrier function which was accompanied by a downregulation of claudin-1, 3, 5, 7 and 8 , and an upregulation of claudin-2, a pore-forming claudin, together with a re-distribution of claudin-5 and -8 off the tight junction domain of the enterocytes in intestinal biopsies of patients with CD [23]. Recent studies showed a strong relationship between intestinal tight junction loss and urinary claudin-3 levels in both a rat hemorrhagic shock model and in patients suffering from IBD or necrotizing enterocolitis, or undergoing major surgery, thereby suggesting that measurement of urinary claudin- 3 can be used to some extent as non-invasive marker for intestinal tight junction loss [17].

\section{Biomarkers of intestinal inflammation and intestinal immunity}

Fecal calprotectin A broad range of pathologies can lead to intestinal inflammation such as neoplasia, IBD, 
IBS, infections, autoimmune diseases, allergies, intestinal hypoperfusion, and selected drugs like non-steroidal anti-inflammatory drugs. Generally, defects or increased permeability of the mucosal barrier will cause intestinal inflammation in response to the enormous number of bacteria present in the bowel. Recruitment of leukocytes into the intestinal wall is important in the pathogenesis of intestinal inflammation. Activated neutrophils infiltrate the mucosa and their products can be detected in feces. Numerous neutrophil derived proteins present in stool have been studied, including calprotectin, lactoferrin, and elastase. The most promising marker is calprotectin, because of its remarkable resistance to proteolytic degradation and its stability in stool kept at room temperature for at least seven days [169]. It constitutes about $60 \%$ of the soluble proteins in human neutrophilic cytosol and is also found in monocytes, macrophages, and ileal tissue eosinophils. It is released during cell activation or cell death and has antiproliferative, antimicrobial, and immunomodulating functions $[169,170]$. Fecal calprotectin is nowadays used in clinical practice to evaluate disease activity in the follow-up of patients treated for active IBD and can be easily performed [171].

Apart from calprotectin, other markers of intestinal immunity such as secretory $\operatorname{IgA}[172]$ and defensins have been proposed as markers of intestinal permeability. Whereas secretory IgA has been examined in patients with celiac disease, defensins have been analyzed mostly in patients with IBD [173]. More recently, fecal human $\beta$-defensin- 2 has been suggested as a marker for intestinal permeability in neonates [174].

Since many years, the macromolecules ovalbumin, which is measured in the serum, and FITC-labeled dextran that is uptaken in the ileum and transported further to the mesenteric lymph nodes, have been used as markers for small intestinal permeability. Likely, such
high-MW markers indicate different qualities of the intestinal barrier than oligosaccharides, but direct comparisons of the different tracers are lacking. On the other hand, their value remains unclear, because in vivo data in humans are scare. Most experiments using ovalbumin or FITC-labeled dextran have been made either in rodents or in Ussing chambers.

Histological approaches Altered tight junction composition can lead to changes in epithelial permeability. Changes in tight junction proteins can be quantified in histological tissue samples by confocal analysis of uniform $\mathrm{Z}$ sections perpendicular to the cell surface of the epithelium (Figure 6). Recently this technique was used to measure changes in tight junction staining in human duodenal tissue and in vitro epithelial cell monolayers following administration of a probiotic [122].

\section{Intestinal permeability - a new target in health and disease?}

A number of different diseases comprising intestinal and extraintestinal diseases have been found to be associated with alterations in the intestinal barrier and increased permeability, respectively (Table 6). Among these, IBD and IBS, critical illness, and - more recently - obesity and metabolic diseases have experienced increasing attention and therefore they will be discuss in this chapter in more detail. Other diseases such as celiac disease need to be mentioned as an example of a disease related to intestinal permeability $[175,176]$. The realization that the barrier is so important, raises the question of what can disrupt the barrier. Even though no final conclusions can be drawn, it became more and more evident that besides nutrients acting as down-regulators of tight junctions or as histone deacetylase (HDAC) inhibitors, also viral infections, toxins, hypoperfusion of the gut play a

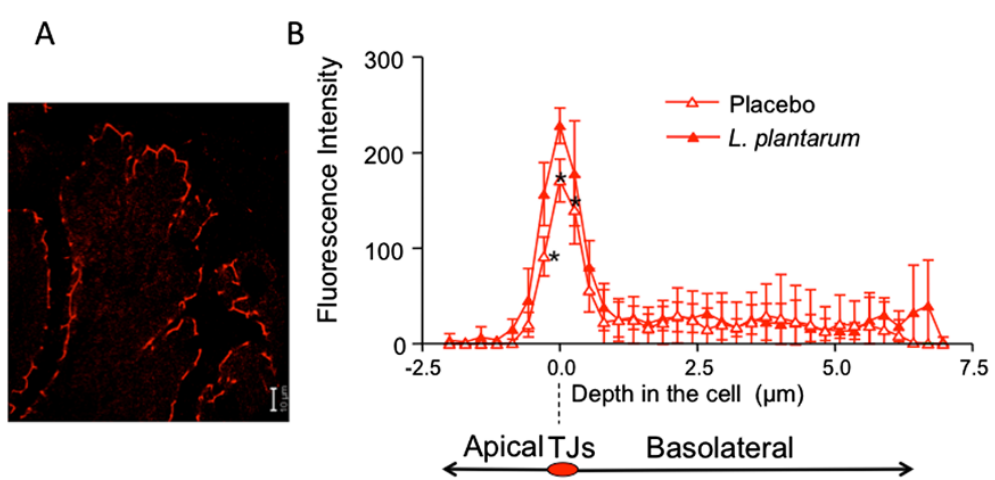

Figure 6 Tight junctions in the intestine. This figure is based on previously published data [115] and shows fluorescent staining of occludin in a tissue section perpendicular to the cell surface of the epithelium (A). The fluorescence intensities of 3 different uniform areas per section were plotted as a function of cell location using the peak fluorescence signal from the tight junction region to align each intensity profile (B). Administration of live L. plantarum to humans significantly increased the fluorescent staining of occludin in the tight junction ( $P<0.05$ for sections indicated ${ }^{*}$ ). 
Table 6 Diseases related to intestinal permeability

\begin{tabular}{ll}
\hline Intestinal & Extraintestinal \\
\hline $\begin{array}{l}\text { Gastric ulcers } \\
\text { Infectious diarrhea }\end{array}$ & Allergies \\
Irritable bowel syndrome; & Acute inflammation (sepsis, SIRS, MOF) \\
functional Gl diseases & \\
$\begin{array}{l}\text { Inflammatory bowel } \\
\text { disease, Celiac disease }\end{array}$ & Chronic inflammation (e.g. arthritis) \\
$\begin{array}{l}\text { Cancer (esophagus, } \\
\text { colorectal) }\end{array}$ & $\begin{array}{l}\text { Obesity-associated metabolic diseases } \\
\text { (NASH, diabetes type I and II, CVD) }\end{array}$ \\
\hline
\end{tabular}

role (Table 7). Lifestyle factors such as living place (farming/country site or urban environment), exercise and drug usage seem to play an important role as well, and they offer new approaches for improving gut barrier function $[4,6]$.

\section{Role of intestinal permeability and probiotics in IBD} Intestinal barrier dysfunction is a main feature of $C D$ and UC $[1,16,138]$. Already 20 years ago it was found that increased intestinal permeability precedes clinical manifestations of $\mathrm{CD}$, but is insufficient to cause disease suggesting other factors being involved [137,177]. Leak flux diarrhea and a facilitated uptake of noxious antigens are the two consequences resulting from an impaired epithelial barrier. Barrier perturbations in IBD comprise alterations in epithelial TJ, i.e. a reduced number of horizontal TJ strands and an altered TJ protein expression and subcellular distribution. Recently, prion protein, a ubiquitous cellular glycoprotein being involved in cell adhesion, was found to be dislocated in IBD supporting the concept that disrupted barrier function contributes to this disorder [178]. Moreover, increased incidence of apoptotic events, epithelial cell shedding, as well as erosions and ulcerations can add to that leakiness [179].

Table 7 Possible causes of impairment of the intestinal barrier

\begin{tabular}{ll}
\hline Nutritional factors & Tight junction downregulation \\
& Histone deacetylase (HDAC) inhibitors \\
& ENS modulators \\
\hline Infections \& toxins & Viral intestinal infections \\
& Environmental toxins \\
& Toxic food \\
\hline "Hygiene hypothesis" & Sterile environment \\
& Lack of farming \\
\hline "Lifestyle hypothesis" & Impaired function and diversity \\
\hline Endogenous factors & of the intestinal microbiota \\
\hline & Hypoperfusion of the intestine \\
& Chronic inflammation/autoimmunity \\
\hline
\end{tabular}

These barrier defects are attributed to enhanced activity of pro-inflammatory cytokines like TNF $\alpha$, INF $\gamma$, IL-1 $\beta$ and IL-13, which are highly expressed in the chronically inflamed intestine. They can be detected in vivo in humans by fluorescein leakage analysis and confocal laser endomicroscopy. Crucially, increased cell shedding causing microerosions and barrier loss as assessed by confocal laser endomicroscopy predicts relapse in CD over a 12 month period [35].

Although the etiology of IBD is far from being clear, chronic inflammation is believed to result from an inadequate immune response as a consequence of genetic predisposition as well as changes in, and altered responses to the intestinal microbiota. On the other hand, an insufficient mucosal response to bacterial stimuli results in an insufficient immune response towards intestinal pathogens. The detailed characterization of barrier defects offers the opportunity to consider and test therapeutic interventions. Beside cytokine antagonists, different plant compounds and probiotics have been shown to stabilize the barrier function by affecting TJ protein expression and distribution [16]. Among the plant compounds, Kiwifruit extracts as well as different polyphenols have been found to exert anti-inflammatory effects in models of IBD and in human disease [180-182].

The first reports on beneficial effects of probiotics in IBD was on E.coli Nissle 1917 supporting maintenance of remission in patients with UC $[183,184]$. The next important finding was that the probiotic mixture VSL\#3 reduces and protects against pouchitis in patients with UC $[185,186]$. Since then, more than 80 RCT have been published showing beneficial effects of probiotics in adults and children with UC, but hardly in CD. For example, VSL\#3 seems to be effective not only in pouchitis, but also in mild to moderate UC not responding to conventional therapy [187]. More recently, the positive findings could be extended to children with active UC, who improved after treatment with the probiotic L.reuteri or VSL\#3 [188,189].

The mechanisms of probiotic effects in IBD is unclear at present, but might involve direct anti-inflammatory effects, e.g. by modulating TLR signaling, or indirect effects such as improvement of the intestinal barrier $[190,191]$.

\section{Role of intestinal permeability and probiotics in IBS}

Intestinal barrier dysfunction has been found to play a pathogenic role not only in IBD, but also in IBS [1]. Most importantly, there is evidence now that increased intestinal permeability is related to low-grade inflammation, visceral hypersensitivity and pain in IBS [192]. In diarrhea-predominant IBS (IBS-D), electron microscopy studies showed cytoskeleton condensation and enlarged intercellular spaces between epithelial cells, providing the morphological basis for increased intestinal permeability in 
IBS. These structural changes were found to correlate both with mast cell activation and symptoms including diarrhea and pain severity [193]. These data confirm and extent earlier observations derived from Ussing chamber experiments showing increased paracellular permeability in colon tissue of IBS patients [194]. The primary cause of the described morpho-functional changes in intestinal permeability remains to be determined. Potential factors include intestinal food allergies, genetic and epigenetic factors, changes in intestinal microbiota. Regardless the cause, mucosal barrier defects determine an increased flow of antigenic substances that challenge the mucosal immune system. Interestingly, several studies have provided evidence of low-grade immune activation and release of inflammatory molecules in IBS which in turn maintain the increase in intestinal permeability [195]. Possibly, the loss of particular TJ proteins such as occludin is a result of increased proteasome-mediated degradation observed in IBS triggered by low-grade inflammation and resulting in increased intestinal permeability [196]. Such data point out the importance of the intestinal barrier in the pathophysiology of IBS and provide evidence for the organic nature of such so-called functional gastrointestinal disorders.

Food, microbiota and bile acids have been discussed as possible inducers of low-grade inflammation and impaired permeability in IBS. In a subgroup of patients, IBS is probably related to food allergy $[197,198]$. Apart from external inducers, endogenous triggers such as mast cell-derived histamine, proteases and eicosanoids can increase intestinal permeability, either directly or via stimulation of neurons of the enteric nervous system [194,199,200]. Serotonin, another biogenic amine besides histamine, produced by enterochromaffin cells in the gut, is another endogenous trigger of pain, inflammation and increased permeability in IBS [201]. Consequently, LX1031, an oral inhibitor of tryptophan hydroxylase, the key enzyme for mucosal serotonin synthesis has been successful for treatment of patients with non-constipating IBS [202].

In conclusion, there is now substantial evidence that increased intestinal permeability is associated with immune activation and symptoms like pain and diarrhea in IBS. Such knowledge paves the way for the identification of new disease biomarkers and novel therapeutic targets in IBS. Apart from mast cell stabilizers [203] and serotonin antagonists [202], also dietetic approaches [204] and probiotics have been found to be effective to some extent. The value of probiotics for treatment in IBS was debated for long time; however, several recent systematic reviews, guidelines and meta-analyses confirmed, despite all gaps and methodological limitations, that selected probiotics are effective in selected subpopulations of patients with IBS [205-209]. In particular, bloating and distension, for with other therapeutic approaches are limited, may improve by probiotic treatment [210,211]. Most interestingly, some of the probiotic trials demonstrated that the effects are correlated with an improvement of the intestinal permeability [212].

\section{Role of intestinal permeability and probiotics in obesity and fatty liver disease}

The new concepts on the pathophysiology of obesity and associated metabolic diseases such as NAFLD and NASH, type 2 diabetes mellitus or cardiovascular diseases, stating that such pathologies are related to the intestinal barrier and the intestinal microbiota, derived predominantly from mouse studies. It could be clearly shown that metabolic diseases are linked to increased intestinal permeability and translocation of bacteria or bacterial products like endotoxin from the intestine to the liver and to other tissues $[96,144,213,214]$. Moreover, it became clear that the microbiota of obese [215,216] and diabetic [217] individuals differs from that of the healthy, lean population. In the meantime, evidence is growing suggesting that these alterations are of functional relevance.

The altered microbiota in obesity and metabolic diseases contributes to an enhanced harvest of energy from nutrients. In particular, energy harvest from food carbohydrates depends on the microbiota, because specific bacteria found to be increased in obese individuals provide enzymes not expressed by host cells and allowing the digestion of otherwise more or less indigestible carbohydrates [218-220]. In type 2 diabetes, the microbiota looses its capacity to generate SCFA from prebiotics [217], which might be a genuine defect or an adaptation to low fiber intake, which has been revealed by several epidemiologic studies [221,222].

The altered intestinal barrier and the subsequent translocation of small amounts of bacteria or bacterial products is now regarded as one important mechanism causing the low-grade inflammation characteristic for metabolic diseases possibly linked to the subsequent infiltration of organs such as liver, muscle and heart muscle with fat [223-226]. Western style diet rich in fat and sugars alters the intestinal barrier in a way resulting in enhanced permeability and elevated endotoxin levels in the portal vein [104,150,227].

The result of such alterations is enhanced infiltration of tissues with bacteria and bacterial products and subsequent tissue inflammation and fat accumulation, which can be observed first in the liver and later on in other tissues such as muscle or heart muscle $[150,219,228]$. Also in peripheral blood and in adipose tissue bacteria or bacterial products can be observed following feeding with energy-rich Western style diet, an observation that might enable to define new bacterial biomarkers of intestinal barrier dysfunction in metabolic diseases [89,214]. However, the two alterations, barrier dysfunction and microbiota alteration, are not necessarily linked, but can occur 
independently [229]. These findings provide a new concept on the pathophysiology of obesity and metabolic diseases that might offer new therapeutic strategies both at the level of diets and of drugs (Figure 7).

Considering these mechanisms it is tempting to speculate that probiotics and prebiotics might have beneficial effects in chronic metabolic disorders. First data derived from experimental studies in mice or from preliminary, human pilot studies indeed point in this direction. For example, possible effects of probiotic bacteria or particular diets on the gut barrier can be studied using organ culture models [230] or feeding models [13,231]. In humans, overfeeding alters the bacterial composition of the commensal microbiota in healthy individuals in a way that results in increased energy harvest from food [232]. The composition of the commensal microbiota might allow the prediction of weight gain in human individuals at risk like pregnant women [233]. In addition, administration of selected prebiotics or probiotics can improve metabolic alterations in animal models of metabolic liver disease $[103,127]$ and in obese human individuals $[234,235]$. Such data suggest that new therapeutic concepts could be developed in the future to support treatment or prevention of obesity and associated diseases.

\section{Role of intestinal permeability and probiotics in the critically ill patient}

Not only chronic diseases such as IBD, IBS and metabolic diseases, but also acute intestinal failure and gramnegative sepsis typically observed in the critically ill patient are associated with an impaired intestinal barrier and marked enhancement of intestinal permeability. For that reason, gram-negative sepsis and subsequent MOF is a common cause of death in the intensive care unit (ICU) [236]. Such complications are seen in patients undergoing major abdominal surgery, but also in trauma patients, burn patients and other ICU patients [237-239].

Hypo-perfusion of the intestinal tract is regarded as the culprit of such complications. Therefore, such events occur also in patients suffering from acute CVD, acute intestinal ischemia of any cause, and acute enterocyte toxicity, e.g. in the course of chemotherapy [240,241]. Also under physiological conditions, a hypo-perfusion of the gut can happen resulting in gut dysfunction, e.g. in the course of exercise [242]. This can be assessed by gastric tonometry and by using appropriate biomarkers of enterocyte damage such as intestinal fatty acid binding protein (I-FABP) and ileal bile acid binding protein (I-BABP). In particular, I-FABP, a cytosolic protein in

\section{Western-style diet \\ Rich in fat (in particular saturated fatty acids) Rich in sugars (in particular fructose) \\ Poor in fibers}

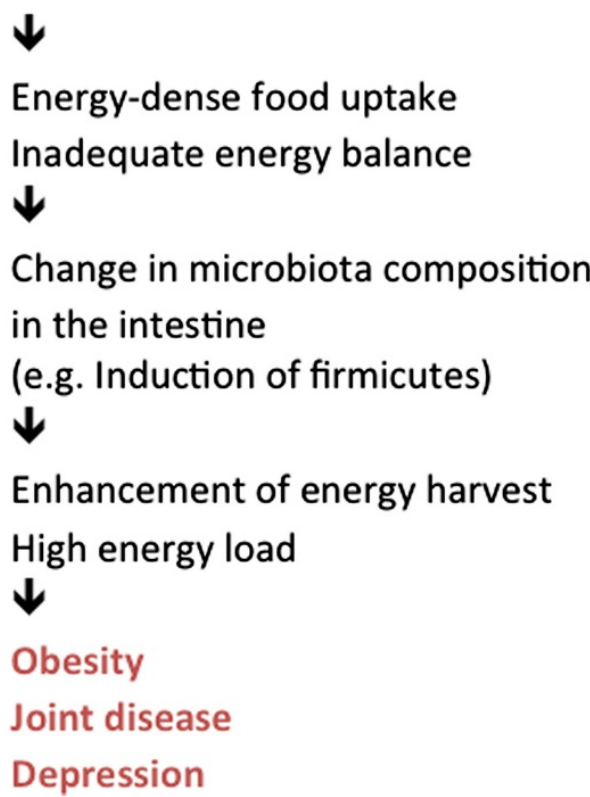

Translocation of bacteria and bacterial products in the intestine

$\downarrow$

Enhanced endotoxin in the portal vein $\downarrow$

Low-grade liver

Inflammation

$\downarrow$

NAFLD / NASH

Insulin resistance

Metabolic disease

Figure 7 Current concepts on the pathophysiology of obesity and metabolic diseases related to the gut. For details see text. 
differentiated enterocytes, which can be measured in urine and plasma, has been confirmed as valuable marker for the early diagnosis of intestinal ischemia [243]. Splanchnic hypo-perfusion can be confirmed in healthy men already after cycling for 60 minutes at $70 \%$ of maximum workload capacity. A $15 \mathrm{~min}$ ischemia causes the appearance of small subepithelial spaces thought to be morphological correlates of an impaired gut barrier [244].

Multiple consequences of enteral ischemia have to be anticipated including mucus barrier loss, bacterial translocation, and enhanced Paneth cell apoptosis causing breakdown of the defensing shield in the intestine $[245,246]$. Fortunately, such alterations are rapidly counteracted, e.g. by increased goblet cell secretory activity in the colon [246]. Even the structural defects such as the subepithelial spaces are quickly restored by lamina propria retraction and zipper-like constriction of the epithelium [247]. Such repair mechanisms have been identified in both rodents and man [248].

The classical treatment of loss of barrier functions in the ICU patient is usage of antibiotics directed against gram-negative bacteria and improvement of intestinal perfusion by catecholamines and volume. If pre- or probiotics can support prevention or treatment of sepsis and MOF is unclear at present. Some studies suggested a beneficial effect of selected probiotics and synbiotics on sepsis complications in patients with major abdominal surgery and in immunocompromised patients who underwent liver transplantation; however, the trials were rather small and limited in number [249-251]. Other studies performed in patients with severe acute pancreatitis yielded conflicting results. Whereas a few initial studies suggested beneficial effects by treatment with synbiotics [252,253], one trial reported increased mortality in the verum group [254]. Although this report hat several methodological limitations, the results underline that otherwise harmless probiotics have to be selected and assessed very carefully in severely ill patients similar to pharmaceutical evaluations. Provided that caution is considered, clinical trials are warranted to support the potential use of probiotics in ICU, namely for prevention of antibiotic-associated and Clostridium difficile-associated diarrhea, ventilator-associated pneumonia and sepsis [255]. A recent meta-analysis drew the conclusion that the administration of probiotics does not significantly reduce ICU or hospital mortality rates but does reduce the incidence of ICU-acquired pneumonia and ICU length of stay [256].

\section{Conclusion}

Apart from IBD, IBS, metabolic diseases and intestinal failure in critically ill patients, other diseases might be related to the gut microbiota and the intestinal barrier such as celiac disease [175,176], colon carcinoma [257] or inflammatory joint diseases [258]. Therefore, alteration of the gut barrier seems to have multiple consequences facilitating the onset of a variety of diseases depending on other hits and on genetic or epigenetic constellations, respectively. The growing significance of the gut barrier and bacterial translocation raises the questions of how we can improve gut barrier functions and gut microbiota.

The research on modulation of gut permeability is just starting. On the other hand, a few approaches have been identified among which are dietetic concepts including prebiotics, as well as probiotics, and possibly also fecal transplantation that can be regarded as an unspecific and global probiotic treatment. Indeed, fecal transplantation now enters clinical medicine, after beneficial effects in patients with therapy-refractory Clostridium difficile infection have been reported [259,260]. Apart from this novel approach, other interventions have been proposed such as particular diets, prebiotics or probiotics (Table 8). Among the diets, some sound promising such as dietary restriction of fat and sugars, or possibly also of poorly absorbed short-chain carbohydrates (FODMAPs) [261-263]. Clearly, more intervention trials are urgently needed now to asses the effects of such substances as preventive or therapeutic agents in different populations and diseases, respectively. For these trials, not only known substances (see Table 8), but also new dietetic components and probiotic agents selected according to their beneficial effects on the gut barrier have to be identified and tested.

To conduct such trials in a scientifically sound way, we need a clear definition and validation of the tools needed to assess gut barrier functions and intestinal permeability. New approaches such as mucus analysis, quantification of translocated bacteria and bacterial products in blood or tissue, and host responses to such alterations, e.g. liver steatosis or fat infection by commensal bacteria, need to be evaluated. Even though European authorities strictly

\begin{tabular}{|c|c|}
\hline \multirow{6}{*}{$\begin{array}{l}\text { Dietetic } \\
\text { approach }\end{array}$} & Avoidance of high amounts of sugar and fat \\
\hline & Avoidance of energy-dense Western-style diet \\
\hline & FODMAP diet \\
\hline & Prebiotics/fibers \\
\hline & Glutamine \\
\hline & Other immune-modulating formula \\
\hline \multirow{3}{*}{$\begin{array}{l}\text { Probiotic } \\
\text { approach }\end{array}$} & Selected probiotics \\
\hline & Probiotic cocktails (multispecies concept) \\
\hline & Synbiotics (combination of probiotics and prebiotics) \\
\hline \multirow[t]{3}{*}{ Drugs/others } & Short-chain fatty acids (SCFA) \\
\hline & Metformin \\
\hline & Quercetin and other flavonoids \\
\hline
\end{tabular}


differ between nutrients and drugs, the new tools to modulate intestinal permeability, such as probiotics, prebiotics or other possibly enriched dietetic components, need clear scientific evaluation independent of their legal classification, which can be questioned from a scientific point of view $[264,265]$. The fact that such substances can be used both for prevention of disease in the general population and for prophylaxis or treatment of disease in defined subpopulations and thus touch both legal categories of substances, a third category should be considered placed between the two existing ones. This new category could be named for example "functional food" usable for both healthy nutrition and medical intervention and requiring trials based on elements established in part in the health claim regulations and in part in the drug laws. A political effort to establish such a new "functional food" category in the European legislation, similar to the one existing in Japan, would support more scientific efforts as well as substantial business efforts to develop this new exiting area of health research further.

Despite many open questions, intestinal permeability becomes an area of growing interest both in basic science and for clinicians, because it might by a valuable new target for disease prevention and therapy. The expert panel agreed on several conclusions:

- Definition of intestinal permeability and intestinal barrier (see Table 1).

- Assessment of intestinal permeability and intestinal barrier (see Tables 4 and 5).

- Given the importance of the physiological and thus the clinical role of the intestinal permeability there is a need for biomarkers that not only reflect lost functionality of the intestine, but also permeability per se and permeability-related functions such as mucus quality. More research is needed to develop reliable non-invasive, rapid diagnostic means.

- The role of microbiota in the regulation of intestinal permeability also requires additional research.

- Food intake is of importance for the intestinal microbiota composition as well as for intestinal permeability, but to which extent? Apart from dietetic approaches, what else can attenuate negative effects of nutrients? What is the preventive capacity of pre- and probiotics?

- The question of how to define a healthy microbiota needs to be addressed. Can an "unhealthy microbiota" affect intestinal permeability in a negative way?

- Are changes in intestinal microbiota in diseases such as IBS or IBD cause or effect of the disease? Can an "unhealthy" intestinal microbiota impair the mucosal immune system through an excessively permeable mucosal barrier, and thus perturb bowel physiology and sensory perception?

- Can we look at the intestinal microbiota as a novel therapeutic tool to improve intestinal permeability and gut health?

\section{Competing interests}

The review is based on a round table discussion held in Frankfurt/Germany in June 2012. The round table was financially supported by Yakult Europe B. V., Schutsluisweg 1, 1332 EN Almere, The Netherlands. The supporting company was not involved in the preparation of the manuscript neither influenced the content of the manuscript in any respect. Apart from this support, the authors declare that they have no competing interests.

\section{Authors' contributions}

All authors participated in the round table discussion on which the article is based. The manuscript was written by SCB and revised and extended by all co-authors. All authors read and approved the final paper.

\section{Acknowledgments}

We acknowledge the support by Dr. Jessica Türk, Neuss, Germany, in documenting the round table discussion the article is based on. Dr. Türk is Scientific Manager of Yakult, Germany. Apart form the financial support by Yakult Europe B.V. indicated in the Competing interest section, the authors received no other funding for the manuscript preparation. The funding body had no role in the writing of the manuscript and in the decision to submit the manuscript for publication.

\section{Author details}

'Department of Nutritional Medicine/Prevention, University of Hohenheim, Fruwirthstrasse 12, 70593 Stuttgart, Germany. ${ }^{2}$ Department of Medical and Surgical Sciences and Centre for Applied Biomedical Research, University of Bologna, Bologna, Italy. ${ }^{3}$ Department of Surgery, Maastricht University Medical Centre, Maastricht, The Netherlands. ${ }^{4}$ Nutricom, Rumpt, The Netherlands. ${ }^{5}$ Department Gastroenterology, Division General Medicine \& Nutrition, Charité Berlin, CBF, Germany. ${ }^{6}$ Institut National de la Santé et de la Recherche Médicale (INSERM) \& Université Paul Sabatier (UPS), Unité Mixte de Recherche (UMR) 1048, Institut de Maladies Métaboliques et Cardiovasculaires (I2MC), Toulouse, France. ${ }^{7}$ Medical University Innsbruck, Department of Internal Medicine I, Innsbruck, Austria. ${ }^{8}$ Norwich Medical School, University of East Anglia, Norwich Research Park, Norwich, UK. ${ }^{9}$ Host-Microbe Interactomics Group, Animal Sciences Department, Wageningen University and Research Centre, Wageningen, The Netherlands.

Received: 27 December 2013 Accepted: 17 October 2014

Published online: 18 November 2014

References

1. Brandtzaeg P: The gut as communicator between environment and host: immunological consequences. Eur J Pharmacol 2011, 668(Suppl 1):S16-S32.

2. Hooper LV, Littman DR, Macpherson AJ: Interactions between the microbiota and the immune system. Science 2012, 336:1268-1273.

3. Maynard CL, Elson CO, Hatton RD, Weaver CT: Reciprocal interactions of the intestinal microbiota and immune system. Nature 2012, 489:231-241.

4. Scaldaferri F, Pizzoferrato M, Gerardi V, Lopetuso L, Gasbarrini A: The gut barrier: new acquisitions and therapeutic approaches. J Clin Gastroenterol 2012, 46(Suppl):S12-S17.

5. Groschwitz KR, Hogan SP: Intestinal barrier function: molecular regulation and disease pathogenesis. J Allergy Clin Immunol 2009, 124:3-20.

6. Bischoff SC: Gut health: a new objective in medicine? BMC Med 2011, 9:24

7. Camilleri M, Madsen K, Spiller R, Greenwood-Van Meerveld B, Verne GN: Intestinal barrier function in health and gastrointestinal disease. Neurogastroenterol Motil 2012, 24:503-512.

8. Massey V, Arteel GE: Acute alcohol-induced liver injury. Front Physiol 2012, 3:193.

9. Moreira AP, Texeira TF, Ferreira AB, Peluzio Mdo C, Alfenas Rde C: Influence of a high-fat diet on gut microbiota, intestinal permeability and metabolic endotoxaemia. Br J Nutr 2012, 108:801-809.

10. Pendyala S, Walker JM, Holt PR: A high-fat diet is associated with endotoxemia that originates from the gut. Gastroenterology 2012, 142:1100-1101. 
11. Tremellen K, Pearce K: Dysbiosis of Gut Microbiota (DOGMA)-a novel theory for the development of Polycystic Ovarian Syndrome. Med Hypotheses 2012, 79:104-112.

12. Seki E, Schnabl B: Role of innate immunity and the microbiota in liver fibrosis: crosstalk between the liver and gut. J Physiol 2012, 590:447-458.

13. Serino M, Luche E, Gres S, Baylac A, Bergé M, Cenac C, Waget A, Klopp P, lacovoni J, Klopp C, Mariette J, Bouchez O, Lluch J, Ouarné F, Monsan P, Valet $\mathrm{P}$, Roques C, Amar J, Bouloumié A, Théodorou V, Burcelin R: Metabolic adaptation to a high-fat diet is associated with a change in the gut microbiota. Gut 2012, 61:543-553.

14. Cummings JH, Antoine JM, Azpiroz F, Bourdet-Sicard R, Brandtzaeg P, Calder PC, Gibson GR, Guarner F, Isolauri E, Pannemans D, Shortt C, Tuijtelaars S, Watzl B: PASSCLAIM-gut health and immunity. Eur J Nutr 2004, 43(Suppl 2):I1118-1|173.

15. Clarke LL: A guide to Ussing chamber studies of mouse intestine. Am J Physiol Gastrointest Liver Physiol 2009, 296:G1151-G1166.

16. Hering NA, Fromm M, Schulzke JD: Determinants of colonic barrier function in inflammatory bowel disease and potential therapeutics. J Physiol 2012, 590:1035-1044.

17. Grootjans J, Thuijls G, Verdam F, Derikx JP, Lenaerts K, Buurman WA: Noninvasive assessment of barrier integrity and function of the human gut. World J Gastrointest Surg 2010, 2:61-69.

18. Wada M, Tamura A, Takahashi N, Tsukita S: Loss of claudins 2 and 15 from mice causes defects in paracellular $\mathrm{Na}+$ flow and nutrient transport in gut and leads to death from malnutrition. Gastroenterology 2013 144:369-380.

19. Tsukita S, Furuse M, Itoh M: Multifunctional strands in tight junctions. Nat Rev Mol Cell Biol 2001, 2:285-293.

20. Raleigh DR, Marchiando AM, Zhang Y, Shen L, Sasaki H, Wang Y, Long M Turner JR: Tight junction-associated MARVEL proteins marveld3, tricellulin, and occludin have distinct but overlapping functions. $\mathrm{Mol} B \mathrm{BiO}$ Cell 2010, 21:1200-1213.

21. Ulluwishewa D, Anderson RC, McNabb WC, Moughan PJ, Wells JM, Roy NC Regulation of tight junction permeability by intestinal bacteria and dietary components. J Nutr 2011, 141:769-776.

22. Turner JR: Intestinal mucosal barrier function in health and disease. Nat Rev Immunol 2009, 9:799-809.

23. Zeissig S, Bürgel N, Günzel D, Richter J, Mankertz J, Wahnschaffe U, Kroesen AJ, Zeitz M, Fromm M, Schulzke JD: Changes in expression and distribution of claudin 2, 5 and 8 lead to discontinuous tight junctions and barrier dysfunction in active Crohn's disease. Gut 2007 56:61-72.

24. Heller F, Florian P, Bojarski C, Richter J, Christ M, Hillenbrand B, Mankertz J, Gitter AH, Bürgel N, Fromm M, Zeitz M, Fuss I, Strober W, Schulzke JD: Interleukin-13 is the key effector Th2 cytokine in ulcerative colitis that affects epithelial tight junctions, apoptosis, and cell restitution. Gastroenterology 2005, 129:550-564.

25. Sato T, Vries RG, Snippert HJ, van de Wetering M, Barker N, Stange DE, van Es JH, Abo A, Kujala P, Peters PJ, Clevers H: Single Lgr5 stem cells build crypt-villus structures in vitro without a mesenchymal niche. Nature 2009 459:262-265.

26. Yen $\mathrm{TH}$, Wright NA: The gastrointestinal tract stem cell niche. Stem Cell Rev 2006, 2:203-212

27. Johansson ME, Thomsson KA, Hansson GC: Proteomic analyses of the two mucus layers of the colon barrier reveal that their main component, the Muc2 mucin, is strongly bound to the Fcgbp protein. J Proteome Res 2009, 8:3549-3557.

28. Johansson ME, Gustafsson JK, Holmén-Larsson J, Jabbar KS, Xia L, Xu H, Ghishan FK, Carvalho FA, Gewirtz AT, Sjövall H, Hansson GC: Bacteria penetrate the normally impenetrable inner colon mucus layer in both murine colitis models and patients with ulcerative colitis. Gut in press.

29. McGuckin MA, Lindén SK, Sutton P, Florin TH: Mucin dynamics and enteric pathogens. Nat Rev Microbiol 2011, 9:265-278

30. Kim YS, Ho SB: Intestinal goblet cells and mucins in health and disease: recent insights and progress. Curr Gastroenterol Rep 2010, 12:319-330

31. Eisenhoffer GT, Loftus PD, Yoshigi M, Otsuna $H$, Chien CB, Morcos PA, Rosenblatt J: Crowding induces live cell extrusion to maintain homeostatic cell numbers in epithelia. Nature 2012, 484:546-549.

32. Gu Y, Forostyan T, Sabbadini R, Rosenblatt J: Epithelial cell extrusion requires the sphingosine-1-phosphate receptor 2 pathway. J Cell Biol 2011, 193:667-676.
33. Marchiando AM, Shen L, Graham WV, Edelblum KL, Duckworth CA, Guan Y, Montrose MH, Turner JR, Watson AJ: The epithelial barrier is maintained by in vivo tight junction expansion during pathologic intestinal epithelial shedding. Gastroenterology 2011, 140:1208-1218.

34. Kiesslich R, Goetz M, Angus EM, Hu Q, Guan Y, Potten C, Allen T, Neurath MF, Shroyer NF, Montrose MH, Watson AJ: Identification of epithelial gaps in human small and large intestine by confocal endomicroscopy. Gastroenterology 2007, 133:1769-1778.

35. Kiesslich R, Duckworth CA, Moussata D, Gloeckner A, Lim LG, Goetz M, Pritchard DM, Galle PR, Neurath MF, Watson AJ: Local barrier dysfunction identified by confocal laser endomicroscopy predicts relapse in inflammatory bowel disease. Gut 2012, 61:1146-1153.

36. Garabedian EM, Roberts LJ, McNevin MS, Gordon Jl: Examining the role of Paneth cells in the small intestine by lineage ablation in transgenic mice. J Biol Chem 1997, 272:23729-23740.

37. Salzman NH: Paneth cell defensins and the regulation of the microbiome: détente at mucosal surfaces. Gut Microbes 2010, 1:401-406.

38. Gersemann M, Wehkamp J, Stange EF: Innate immune dysfunction in inflammatory bowel disease. J Intern Med 2012, 271:421-428.

39. Mestas J, Hughes CC: Of mice and not men: differences between mouse and human immunology. J Immunol 2004, 172:2731-2738.

40. Vaishnava S, Yamamoto M, Severson KM, Ruhn KA, Yu X, Koren O, Ley R, Wakeland EK, Hooper LV: The antibacterial lectin Reglllgamma promotes the spatial segregation of microbiota and host in the intestine. Science 2011, 334:255-258.

41. Macpherson AJ, Gatto D, Sainsbury E, Harriman GR, Hengartner H, Zinkernage RM: A primitive T cell-independent mechanism of intestinal mucosal IgA responses to commensal bacteria. Science 2000, 288:2222-2226.

42. Macpherson AJ, McCoy KD, Johansen FE, Brandtzaeg P: The immune geography of IgA induction and function. Mucosal Immunol 2008, $1: 11-22$.

43. Suzuki K, Fagarasan S: How host-bacterial interactions lead to $\lg A$ synthesis in the gut. Trends Immunol 2008, 29:523-531.

44. Fagarasan S, Honjo T: T-Independent immune response: new aspects of $B$ cell biology. Science 2000, 290:89-92.

45. Weller S, Braun MC, Tan BK, Rosenwald A, Cordier C, Conley ME, Plebani A, Kumararatne DS, Bonnet D, Tournilhac O, Tchernia G, Steiniger B, Staudt LM, Casanova JL, Reynaud CA, Weill JC: Human blood IgM "memory" B cells are circulating splenic marginal zone $B$ cells harboring a prediversified immunoglobulin repertoire. Blood 2004, 104:3647-3654.

46. Shroff KE, Meslin K, Cebra JJ: Commensal enteric bacteria engender a selflimiting humoral mucosal immune response while permanently colonizing the gut. Infect Immun 1995, 63:3904-3913.

47. Macpherson AJ, Hunziker L, McCoy K, Lamarre A: IgA responses in the intestinal mucosa against pathogenic and non-pathogenic microorganisms. Microbes Infect 2001, 3:1021-1035.

48. Bischoff SC, Mailer R, Pabst O, Weier G, Sedlik W, Li Z, Chen JJ, Murphy DL, Gershon MD: Role of serotonin in intestinal inflammation: knockout of serotonin reuptake transporter exacerbates 2,4,6-trinitrobenzene sulfonic acid colitis in mice. Am J Physiol 2009, 296:G685-G695.

49. Haub S, Ritze Y, Bergheim I, Pabst O, Gershon MD, Bischoff SC: Enhancement of intestinal inflammation in mice lacking interleukin 10 by deletion of the serotonin reuptake transporter. Neurogastroentero/ Motil 2010, 22:826-834

50. Haub S, Kanuri G, Volynets V, Brune T, Bischoff SC, Bergheim I: Serotonin reuptake transporter (SERT) plays a critical role in the onset of fructoseinduced hepatic steatosis in mice. Am J Physiol Gastrointest Liver Physiol 2010, 298:335-344.

51. Bischoff SC: Physiological and pathophysiological functions of intestinal mast cells. Semin Immunopathol 2009, 31:185-205.

52. Alhamoruni A, Wright $\mathrm{KL}$, Larvin M, O'Sullivan SE: Cannabinoids mediate opposing effects on inflammation-induced intestinal permeability. $\mathrm{Br} J$ Pharmacol 2012, 165:2598-2610.

53. Zoppi S, Madrigal JL, Pérez-Nievas BG, Marín-Jiménez I, Caso JR, Alou L, García-Bueno B, Colón A, Manzanares J, Gómez-Lus ML, Menchén L, Leza JC: Endogenous cannabinoid system regulates intestinal barrier function in vivo through cannabinoid type 1 receptor activation. Am J Physiol Gastrointest Liver Physiol 2012, 302:G565-G571.

54. Muccioli GG, Naslain D, Bäckhed F, Reigstad CS, Lambert DM, Delzenne NM, Cani PD: The endocannabinoid system links gut microbiota to adipogenesis. Mol Syst Biol 2010, 6:392. 
55. Bäckhed F, Ley RE, Sonnenburg JL, Peterson DA, Gordon Jl: Host-bacterial mutualism in the human intestine. Science 2005, 307:1915-1920.

56. Eckburg PB, Bik EM, Bernstein CN, Purdom E, Dethlefsen L, Sargent M, Gill $\mathrm{SR}$, Nelson KE, Relman DA: Diversity of the human intestinal microbial flora. Science 2005, 308:1635-1638.

57. Ley RE, Hamady M, Lozupone C, Turnbaugh PJ, Ramey RR, Bircher JS, Schlegel ML, Tucker TA, Schrenzel MD, Knight R, Gordon Jl: Evolution of mammals and their gut microbes. Science 2008, 320:1647-1651.

58. Arumugam M, Raes J, Pelletier E, Le Paslier D, Yamada T, Mende DR, Fernandes GR, Tap J, Bruls T, Batto JM, Bertalan M, Borruel N, Casellas F, Fernandez L, Gautier L, Hansen T, Hattori M, Hayashi T, Kleerebezem M, Kurokawa K, Leclerc M, Levenez F, Manichanh C, Nielsen HB, Nielsen T, Pons N, Poulain J, Qin J, Sicheritz-Ponten T, Tims S, et al: Enterotypes of the human gut microbiome. Nature 2011, 473:174-180.

59. Caporaso JG, Lauber CL, Costello EK, Berg-Lyons D, Gonzalez A, Stombaugh J, Knights D, Gajer P, Ravel J, Fierer N, Gordon Jl, Knight R: Moving pictures of the human microbiome. Genome Biol 2011, 12:R50

60. Wells JM, Rossi O, Meijerink M, van Baarlen P: Epithelial crosstalk at the microbiota-mucosal interface. Proc Natl Acad Sci U S A 2011 108(Suppl 1):4607-4614.

61. Hooper LV, Macpherson AJ: Immune adaptations that maintain homeostasis with the intestinal microbiota. Nat Rev Immunol 2010, 10:159-169.

62. Machiels K, Joossens M, Sabino J, De Preter V, Arijs I, Eeckhaut V, Ballet V, Claes K, Van Immerseel F, Verbeke K, Ferrante M, Verhaegen J, Rutgeerts P, Vermeire S: A decrease of the butyrate-producing species Roseburia hominis and Faecalibacterium prausnitzii defines dysbiosis in patients with ulcerative colitis. Gut 2013. doi:10.1136/gutjnl-2013-304833. [Epub ahead of print].

63. Miquel S, Martín R, Rossi O, Bermúdez-Humarán LG, Chatel JM, Sokol H, Thomas M, Wells JM, Langella P: Faecalibacterium prausnitzii and human intestinal health. Curr Opin Microbiol 2013, 16:255-261.

64. Maslowski KM, Vieira AT, Ng A, Kranich J, Sierro F, Yu D, Schilter HC, Rolph MS, Mackay F, Artis D, Xavier RJ, Teixeira MM, Mackay CR: Regulation of inflammatory responses by gut microbiota and chemoattractant receptor GPR43. Nature 2009, 461:1282-1286.

65. Chassaing B, Darfeuille-Michaud A: The commensal microbiota and enteropathogens in the pathogenesis of inflammatory bowel diseases. Gastroenterology 2011, 140:1720-1728.

66. Chow J, Tang H, Mazmanian SK: Pathobionts of the gastrointestinal microbiota and inflammatory disease. Curr Opin Immunol 2011, 23:473-480

67. Pearson JP, Brownlee IA: The interaction of large bowel microflora with the colonic mucus barrier. Int J Inflam 2010, 2010:321426.

68. Ganesh BP, Klopfleisch R, Loh G, Blaut M: Commensal Akkermansia muciniphila exacerbates gut inflammation in Salmonella Typhimuriuminfected gnotobiotic mice. PLOS One 2013, 8:e74963.

69. Lindstedt G, Lindstedt S, Gustafsson BE: Mucus in intestinal contents of germfree rats. J Exp Med 1965, 121:201-213.

70. Amieva MR, Vogelmann R, Covacci A, Tompkins LS, Nelson WJ, Falkow S: Disruption of the epithelial apical-junctional complex by Helicobacter pylori CagA. Science 2003, 300:1430-1434.

71. Bagnoli F, Buti L, Tompkins L, Covacci A, Amieva MR: Helicobacter pylori CagA induces a transition from polarized to invasive phenotypes in MDCK cells. Proc Natl Acad Sci U S A 2005, 102:16339-16344

72. Saadat I, Higashi H, Obuse C, Umeda M, Murata-Kamiya N, Saito Y, Lu H, Ohnishi N, Azuma T, Suzuki A, Ohno S, Hatakeyama M: Helicobacter pylori CagA targets PAR1/MARK kinase to disrupt epithelial cell polarity. Nature 2007, 447:330-333.

73. Wroblewski LE, Shen L, Ogden S, Romero-Gallo J, Lapierre LA, Israel DA, Turner JR, Peek RM Jr: Helicobacter pylori dysregulation of gastric epithelial tight junctions by urease-mediated myosin II activation. Gastroenterology 2009, 136:236-246

74. Lapointe TK, O'Connor PM, Jones NL, Menard D, Buret AG: Interleukin-1 receptor phosphorylation activates Rho kinase to disrupt human gastric tight junctional claudin-4 during Helicobacter pylori infection. Cell Microbiol 2010, 12:692-703.

75. Alto NM, Shao F, Lazar CS, Brost RL, Chua G, Mattoo S, McMahon SA Ghosh P, Hughes TR, Boone C, Dixon JE: Identification of a bacterial type III effector family with $\mathrm{G}$ protein mimicry functions. Cell 2006, 124:133-145.
76. Arbeloa A, Bulgin RR, MacKenzie G, Shaw RK, Pallen MJ, Crepin VF, Berger CN, Frankel G: Subversion of actin dynamics by EspM effectors of attaching and effacing bacterial pathogens. Cell Microbiol 2008, 10:1429-1441.

77. Simovitch M, Sason H, Cohen S, Zahavi EE, Melamed-Book N, Weiss A, Aroeti $B$, Rosenshine I: EspM inhibits pedestal formation by enterohaemorrhagic Escherichia coli and enteropathogenic E. coli and disrupts the architecture of a polarized epithelial monolayer. Cell Microbiol 2010, 12:489-505.

78. Arbeloa A, Garnett J, Lillington J, Bulgin RR, Berger CN, Lea SM, Matthews S, Frankel G: EspM2 is a RhoA guanine nucleotide exchange factor. Cell Microbiol 2010, 12:654-664.

79. Thanabalasuriar A, Koutsouris A, Weflen A, Mimee M, Hecht G, Gruenheid S: The bacterial virulence factor NleA is required for the disruption of intestinal tight junctions by enteropathogenic Escherichia coli. Cell Microbiol 2010, 12:31-41.

80. Yarbrough ML, Li Y, Kinch LN, Grishin NV, Ball HL, Orth K: AMPylation of Rho GTPases by Vibrio VopS disrupts effector binding and downstream signaling. Science 2009, 323:269-272.

81. Caburlotto G, Lleò MM, Hilton T, Huq A, Colwell RR, Kaper JB: Effect on human cells of environmental Vibrio parahaemolyticus strains carrying type III secretion system. Infect Immun 2010, 78:3280-3287.

82. Boyle EC, Brown NF, Finlay BB: Salmonella enterica serovar Typhimurium effectors SopB, SopE, SopE2 and SipA disrupt tight junction structure and function. Cell Microbiol 2006, 8:1946-1957.

83. Chen ML, Pothoulakis C, LaMont JT: Protein kinase $C$ signaling regulates ZO-1 translocation and increased paracellular flux of T84 colonocytes exposed to Clostridium difficile toxin A. J Biol Chem 2002, 277:4247-4254

84. Wu S, Lim KC, Huang J, Saidi RF, Sears CL: Bacteroides fragilis enterotoxin cleaves the zonula adherens protein, E-cadherin. Proc Natl Acad Sci U S A 1998, 95:14979-14984.

85. Wu Z, Nybom P, Magnusson KE: Distinct effects of Vibrio cholerae haemagglutinin/protease on the structure and localization of the tight junction-associated proteins occludin and ZO-1. Cell Microbiol 2000, 2:11-17.

86. Ng KM, Ferreyra JA, Higginbottom SK, Lynch JB, Kashyap PC, Gopinath S, Naidu N, Choudhury B, Weimer BC, Monack DM, Sonnenburg JL: Microbiota-liberated host sugars facilitate post-antibiotic expansion of enteric pathogens. Nature 2013, 502:96-99.

87. Turner JR: Show me the pathway! Regulation of paracellular permeability by Na-glucose cotransport. Adv Drug Deliv Rev 2000, 41:265-281.

88. Serino M, Luche E, Chabo C, Amar J, Burcelin R: Intestinal microflora and metabolic diseases. Diabetes Metab 2009, 35:262-272.

89. Amar J, Serino M, Lange C, Chabo C, lacovoni J, Mondot S, Lepage P, Klopp C, Mariette J, Bouchez O, Perez L, Courtney M, Marre M, Klopp P, Lantieri O, Doré J, Charles M, Balkau B, Burcelin R, D.E.S.I.R. Study Group: Involvement of tissue bacteria in the onset of diabetes in humans: evidence for a concept. Diabetologia 2011, 54:3055-3061.

90. Serino M, Chabo C, Burcelin R: Intestinal MicrobiOMICS to define health and disease in human and mice. Curr Pharm Biotechnol 2012, 13:746-758.

91. Cani PD, Delzenne NM: The role of the gut microbiota in energy metabolism and metabolic disease. Curr Pharm Des 2009, 15:1546-1558.

92. Delzenne NM, Neyrinck AM, Cani PD: Modulation of the gut microbiota by nutrients with prebiotic properties: consequences for host health in the context of obesity and metabolic syndrome. Microb Cell Fact 2011, 10(Suppl 1):S10.

93. Spruss A, Bergheim I: Dietary fructose and intestinal barrier: potential risk factor in the pathogenesis of nonalcoholic fatty liver disease. $J$ Nutr Biochem 2009, 20:657-662.

94. Amit-Romach E, Uni Z, Cheled S, Berkovich Z, Reifen R: Bacterial population and innate immunity-related genes in rat gastrointestinal tract are altered by vitamin A-deficient diet. J Nutr Biochem 2009, 20:70-77.

95. Warden RA, Noltorp RS, Francis JL, Dunkley PR, O'Loughlin EV: Vitamin A deficiency exacerbates methotrexate-induced jejunal injury in rats. J Nutr 1997, 127:770-776

96. Lima AA, Soares AM, Lima NL, Mota RM, Maciel BL, Kvalsund MP, Barrett LJ, Fitzgerald RP, Blaner WS, Guerrant RL: Effects of vitamin A supplementation on intestinal barrier function, growth, total parasitic, and specific Giardia spp infections in Brazilian children: a prospective randomized, double-blind, placebo-controlled trial. J Pediatr Gastroenterol Nutr 2010, 50:309-315. 
97. Ulitsky A, Ananthakrishnan AN, Naik A, Skaros S, Zadvornova Y, Binion DG, Issa M: Vitamin D deficiency in patients with inflammatory bowel disease: Association with disease activity and quality of life. JPEN J Parenter Enteral Nutr 2011, 35:308-316.

98. Kong J, Zhang Z, Musch MW, Ning G, Sun J, Hart J, Bissonnette M, Li YC: Novel role of the vitamin $D$ receptor in maintaining the integrity of the intestinal mucosal barrier. Am J Physiol Gastrointest Liver Physiol 2008, 294:208-216.

99. Ploger S, Stumpff F, Penner GB, Schulzke JD, Gäbel G, Martens H, Shen Z, Günzel D, Aschenbach JR: Microbial butyrate and its role for barrier function in the gastrointestinal tract. Ann N Y Acad Sci 2012, 1258:52-59.

100. Venkatraman A, Ramakrishna BS, Pulimood AB, Patra S, Murthy S: Increased permeability in dextran sulphate colitis in rats: time course of development and effect of butyrate. Scand J Gastroenterol 2000, 35:1053-1059.

101. Searle LE, Cooley WA, Jones G, Nunez A, Crudgington B, Weyer U, Dugdale AH, Tzortzis G, Collins JW, Woodward MJ, La Ragione RM: Purified galactooligosaccharide, derived from a mixture produced by the enzymic activity of Bifidobacterium bifidum, reduces Salmonella enterica serovar Typhimurium adhesion and invasion in vitro and in vivo. $J$ Med Microbiol 2010, 59:1428-1439.

102. Zhong Y, Cai D, Cai W, Geng S, Chen L, Han T: Protective effect of galactooligosaccharide-supplemented enteral nutrition on intestinal barrier function in rats with severe acute pancreatitis. Clin Nutr 2009, 28:575-580.

103. Pachikian BD, Essaghir A, Demoulin JB, Catry E, Neyrinck AM, Dewulf EM, Sohet FM, Portois L, Clerbaux LA, Carpentier YA, Possemiers S, Bommer GT Cani PD, Delzenne NM: Prebiotic approach alleviates hepatic steatosis: implication of fatty acid oxidative and cholesterol synthesis pathways. Mol Nutr Food Res 2013, 57:347-359.

104. Spruss A, Kanuri G, Wagnerberger S, Haub S, Bischoff SC, Bergheim I: Toll-like receptor 4 is involved in the development of fructose-induced hepatic steatosis in mice. Hepatology 2009, 50:1094-1104.

105. Spruss A, Kanuri G, Stahl C, Bischoff SC, Bergheim I: Metformin protects against the development of fructose-induced steatosis in mice: role of the intestinal barrier function. Lab Invest 2012, 92:1020-1032

106. Amasheh M, Andres S, Amasheh S, Fromm M, Schulzke JD: Barrier effects of nutritional factors. Ann N Y Acad Sci 2009, 1165:267-273.

107. Amasheh M, Luettig J, Amasheh S, Zeitz M, Fromm M, Schulzke JD: Effects of quercetin studied in colonic HT-29/B6 cells and rat intestine in vitro. Ann N Y Acad Sci 2012, 1258:100-107.

108. Rosenfeldt V, Benfeldt E, Valerius NH, Paerregaard A, Michaelsen KF: Effect of probiotics on gastrointestinal symptoms and small intestinal permeability in children with atopic dermatitis. J Pediatr 2004, 145:612-616.

109. Stratiki Z, Costalos C, Sevastiadou S, Kastanidou O, Skouroliakou M Giakoumatou A, Petrohilou V: The effect of a bifidobacter supplemented bovine milk on intestinal permeability of preterm infants. Early Hum Dev 2007, 83:575-579.

110. Madsen K, Cornish A, Soper P, McKaigney C, Jijon H, Yachimec C, Doyle J, Jewell $L$, De Simone C: Probiotic bacteria enhance murine and human intestinal epithelial barrier function. Gastroenterology 2001, 121:580-591.

111. Zareie M, Johnson-Henry K, Jury J, Yang PC, Ngan BY, McKay DM, Soderholm JD, Perdue MH, Sherman PM: Probiotics prevent bacterial translocation and improve intestinal barrier function in rats following chronic psychological stress. Gut 2006, 55:1553-1560.

112. Zyrek AA, Cichon C, Helms S, Enders C, Sonnenborn U, Schmidt MA: Molecular mechanisms underlying the probiotic effects of Escherichia coli Nissle 1917 involve ZO-2 and PKCzeta redistribution resulting in tight junction and epithelial barrier repair. Cell Microbio/ 2007, 9:804-816.

113. Ukena SN, Singh A, Dringenberg U, Engelhardt R, Seidler U, Hansen W, Bleich A, Bruder D, Franzke A, Rogler G, Suerbaum S, Buer J, Gunzer F, Westendorf AM: Probiotic Escherichia coli Nissle 1917 inhibits leaky gut by enhancing mucosal integrity. PLoS One 2007, 2:e1308.

114. Corridoni D, Pastorelli L, Mattioli B, Locovei S, Ishikawa D, Arseneau KO, Chieppa M, Cominelli F, Pizarro TT: Probiotic bacteria regulate intestinal epithelial permeability in experimental ileitis by a TNF-dependent mechanism. PLoS One 2012, 7:e42067.

115. Anderson RC, Cookson AL, McNabb WC, Park Z, McCann MJ, Kelly WJ, Roy NC: Lactobacillus plantarum MB452 enhances the function of the intestinal barrier by increasing the expression levels of genes involved in tight junction formation. BMC Microbiol 2010, 10:316.
116. Berkes J, Viswanathan VK, Savkovic SD, Hecht G: Intestinal epithelial responses to enteric pathogens: effects on the tight junction barrier, ion transport, and inflammation. Gut 2003, 52:439-451.

117. Resta-Lenert S, Barrett KE: Probiotics and commensals reverse TNF-alphaand IFN-gamma-induced dysfunction in human intestinal epithelial cells. Gastroenterology 2006, 130:731-746.

118. Qin H, Zhang Z, Hang X, Jiang Y: L. plantarum prevents enteroinvasive Escherichia coli-induced tight junction proteins changes in intestinal epithelial cells. BMC Microbiol 2009, 9:63.

119. Moorthy G, Murali MR, Devaraj SN: Lactobacilli facilitate maintenance of intestinal membrane integrity during Shigella dysenteriae 1 infection in rats. Nutrition 2009, 25:350-358.

120. Anderson RC, Cookson AL, McNabb WC, Kelly WJ, Roy NC: Lactobacillus plantarum DSM 2648 is a potential probiotic that enhances intestinal barrier function. FEMS Microbiol Lett 2010, 309:184-192.

121. Mathias A, Duc M, Favre L, Benyacoub J, Blum S, Corthésy B: Potentiation of polarized intestinal Caco-2 cell responsiveness to probiotics complexed with secretory IgA. J Biol Chem 2010, 285:33906-33913.

122. Karczewski J, Troost FJ, Konings I, Dekker J, Kleerebezem M, Brummer RJ, Wells JM: Regulation of human epithelial tight junction proteins by Lactobacillus plantarum in vivo and protective effects on the epithelial barrier. Am J Physiol Gastrointest Liver Physiol 2010, 298:G851-G859.

123. Miyauchi E, O'Callaghan J, Buttó LF, Hurley G, Melgar S, Tanabe S, Shanahan F, Nally K, O'Toole PW: Mechanism of protection of transepithelial barrier function by Lactobacillus salivarius: strain dependence and attenuation by bacteriocin production. Am J Physiol Gastrointest Liver Physiol 2012, 303:G1029-G1041.

124. Wang Y, Liu Y, Sidhu A, Ma Z, McClain C, Feng W: Lactobacillus rhamnosus GG culture supernatant ameliorates acute alcohol-induced intestinal permeability and liver injury. Am J Physiol Gastrointest Liver Physiol 2012, 303: G32-G41.

125. Zakostelska Z, Kverka M, Klimesova K, Rossmann P, Mrazek J, Kopecny J, Hornova M, Srutkova D, Hudcovic T, Ridl J, Tlaskalova-Hogenova H: Lysate of probiotic Lactobacillus casei DN-114 001 ameliorates colitis by strengthening the gut barrier function and changing the gut microenvironment. PLoS One 2011, 6:e27961.

126. Agostini $S$, Goubern M, Tondereau V, Salvador-Cartier $C$, Bezirard V, Lévèque M, Keränen H, Theodorou V, Bourdu-Naturel S, Goupil-Feuillerat N, LegrainRaspaud S, Eutamene $\mathrm{H}$ : A marketed fermented dairy product containing Bifidobacterium lactis CNCM I-2494 suppresses gut hypersensitivity and colonic barrier disruption induced by acute stress in rats. Neurogastroenterol Motil 2012, 24:376-e172.

127. Wagnerberger S, Spruss A, Kanuri G, Stahl C, Schröder M, Vetter W Bischoff SC, Bergheim I: Lactobacillus casei Shirota protects from fructose-induced liver steatosis: a mouse model. J Nutr Biochem 2013, 24:531-538

128. Veltman K, Hummel S, Cichon C, Sonnenborn U, Schmidt MA: Identification of specific miRNAs targeting proteins of the apical junctional complex that simulate the probiotic effect of E. coli Nissle 1917 on T84 epithelial cells. Int J Biochem Cell Biol 2012, 44:341-349.

129. Tai $\mathrm{YH}$, Tai $\mathrm{CY}$ : The conventional short-circuiting technique under-shortcircuits most epithelia. J Membr Biol 1981, 59:173-177

130. Parassol N, Freitas M, Thoreux K, Dalmasso G, Bourdet-Sicard R, Rampal P. Lactobacillus casei DN-114 001 inhibits the increase in paracellular permeability of enteropathogenic Escherichia coli-infected T84 cells. Res Microbiol 2005, 156:256-262.

131. Llopis M, Antolin M, Carol M, Borruel N, Casellas F, Martinez C, Espín-Basany E, Guarner F, Malagelada JR: Lactobacillus casei downregulates commensals' inflammatory signals in Crohn's disease mucosa. Inflamm Bowel Dis 2009, 15:275-283.

132. Yoshida S, Matsui M, Shirouzu Y, Fujita H, Yamana H, Shirouzu K: Effects of glutamine supplements and radiochemotherapy on systemic immune and gut barrier function in patients with advanced esophageal cancer. Ann Surg 1998, 227:485-491.

133. Norman K, Pirlich M, Schulzke JD, Smoliner C, Lochs $H$, Valentini L, Bühner $S$ : Increased intestinal permeability in malnourished patients with liver cirrhosis. Eur J Clin Nutr 2012, 66:1116-1119.

134. Anderson AD, Jain PK, Fleming S, Poon P, Mitchell CJ, MacFie J: Evaluation of a triple sugar test of colonic permeability in humans. Acta Physio/ scand 2004, 182:171-177. 
135. Meddings JB, Sutherland LR, Byles NI, Wallace JL: Sucrose: a novel permeability marker for gastroduodenal disease. Gastroenterology 1993, 104:1619-1626.

136. van Wijck K, Verlinden TJ, van Eijk HM, Dekker J, Buurman WA, Dejong CH, Lenaerts K: Novel multi-sugar assay for site-specific gastrointestinal permeability analysis: a randomized controlled crossover trial. Clin Nutr 2013, 32:245-251.

137. Wyatt J, Oberhuber G, Pongratz S, Püspök A, Moser G, Novacek G, Lochs H, Vogelsang $\mathrm{H}$ : Increased gastric and intestinal permeability in patients with Crohn's disease. Am J Gastroenterol 1997, 92:1891-1896.

138. Mankertz J, Schulzke JD: Altered permeability in inflammatory bowel disease: pathophysiology and clinical implications. Curr Opin Gastroenterol 2007, 23:379-383.

139. Smecuol E, Bai JC, Vazquez H, Kogan Z, Cabanne A, Niveloni S, Pedreira S, Boerr L, Mauriño E, Meddings JB: Gastrointestinal permeability in celiac disease. Gastroenterology 1997, 112:1129-1136

140. Troncone R, Caputo N, Florio G, Finelli E: Increased intestinal sugar permeability after challenge in children with cow's milk allergy or intolerance. Allergy 1994, 49:142-146.

141. Ventura MT, Polimeno L, Amoruso AC, Gatti F, Annoscia E, Marinaro M, Di Leo E, Matino MG, Buquicchio R, Bonini S, Tursi A, Francavilla A: Intestinal permeability in patients with adverse reactions to food. Dig Liver Dis 2006, 38:732-736.

142. Harris CE, Griffiths RD, Freestone N, Billington D, Atherton ST, Macmillan RR: Intestinal permeability in the critically ill. Intensive Care Med 1992, 18:38-41.

143. Ohri SK, Somasundaram S, Koak Y, Macpherson A, Keogh BE, Taylor KM, Menzies IS, Bjarnason I: The effect of intestinal hypoperfusion on intestinal absorption and permeability during cardiopulmonary bypass. Gastroenterology 1994, 106:318-323.

144. Kerckhoffs AP, Akkermans LM, de Smet MB, Besselink MG, Hietbrink F, Bartelink IH, Busschers WB, Samsom M, Renooij W: Intestinal permeability in irritable bowel syndrome patients: effects of NSAIDs. Dig Dis Sci 2010, 55:716-723.

145. Ammori BJ, Leeder PC, King RF, Barclay GR, Martin IG, Larvin M, McMahon $\mathrm{MJ}$ : Early increase in intestinal permeability in patients with severe acute pancreatitis: correlation with endotoxemia, organ failure, and mortality. J Gastrointest Surg 1999, 3:252-262.

146. Lee S, Son SC, Han MJ, Kim WJ, Kim SH, Kim HR, Jeon WK, Park KH, Shin MG: Increased intestinal macromolecular permeability and urine nitrite excretion associated with liver cirrhosis with ascites. World J Gastroenterol 2008, 14:3884-3890.

147. Solligård E, Juel IS, Spigset O, Romundstad P, Grønbech JE, Aadahl P: Gut luminal lactate measured by microdialysis mirrors permeability of the intestinal mucosa after ischemia. Shock 2008, 29:245-251.

148. Jenkins RT, Ramage JK, Jones DB, Collins SM, Goodacre RL, Hunt RH: Small bowel and colonic permeability to $51 \mathrm{Cr}$-EDTA in patients with active inflammatory bowel disease. Clin Invest Med 1988, 11:151-155.

149. Bates DW, Parsonnet J, Ketchum PA, Miller EB, Novitsky TJ, Sands K, Hibberd PL, Graman PS, Lanken PN, Schwartz JS, Kahn K, Snydman DR, Moore R, Black E, Platt R: Limulus amebocyte lysate assay for detection of endotoxin in patients with sepsis syndrome: AMCC Sepsis Project Working Group. Clin Infect Dis 1998, 27:582-591.

150. Bergheim I, Weber S, Vos M, Krämer S, Volynets V, Kaserouni S, McClain CJ, Bischoff SC: Antibiotics protect against fructose-induced hepatic lipid accumulation in mice: role of endotoxin. $J$ Hepatol 2008, 48:983-992.

151. Thuy S, Ladurner R, Volynets V, Wagner S, Strahl S, Königsrainer A, Maier KP, Bischoff SC, Bergheim I: Nonalcoholic fatty liver disease in humans is associated with increased plasma endotoxin and plasminogen activator inhibitor 1 concentrations and with fructose intake. J Nutr 2008, 138:1452-1455.

152. Strutz F, Heller G, Krasemann K, Krone B, Müller GA: Relationship of antibodies to endotoxin core to mortality in medical patients with sepsis syndrome. Intensive Care Med 1999, 25:435-444.

153. Bennett-Guerrero E, Barclay GR, Weng PL, Bodian CA, Feierman DE, VelaCantos F, Mythen MG: Endotoxin-neutralizing capacity of serum from cardiac surgical patients. J Cardiothorac Vasc Anesth 2001, 15:451-454

154. Lewis K, Lutgendorff F, Phan V, Söderholm JD, Sherman PM, McKay DM: Enhanced translocation of bacteria across metabolically stressed epithelia is reduced by butyrate. Inflamm Bowel Dis 2010, 16:1138-1148.
155. Wang HB, Wang PY, Wang X, Wan YL, Liu YC: Butyrate enhances intestinal epithelial barrier function via up-regulation of tight junction protein Claudin-1 transcription. Dig Dis Sci 2012, 57:3126-3135.

156. Troeger H, Richter JF, Beutin L, Günzel D, Dobrindt U, Epple HJ, Gitter AH, Zeitz M, Fromm M, Schulzke JD: Escherichia coli alpha-haemolysin induces focal leaks in colonic epithelium: a novel mechanism of bacterial translocation. Cell Microbiol 2007, 9:2530-2540.

157. Verdam FJ, Dallinga JW, Driessen A, Jonge CD, Moonen EJ, van Berkel JB, Luijk J, Bouvy ND, Buurman WA, Rensen SS, Greve JW, Schooten FJ: Nonalcoholic steatohepatitis: a non-invasive diagnosis by analysis of exhaled breath. J Hepatol 2013, 58:543-548.

158. Crenn P, Coudray-Lucas C, Thuillier F, Cynober L, Messing B: Postabsorptive plasma citrulline concentration is a marker of absorptive enterocyte mass and intestinal failure in humans. Gastroenterology 2000, 119:1496-1505.

159. van Vliet MJ, Tissing WJ, Rings EH, Koetse HA, Stellaard F, Kamps WA, de Bont ES: Citrulline as a marker for chemotherapy induced mucosal barrier injury in pediatric patients. Pediatr Blood Cancer 2009, 53:1188-1194.

160. Lutgens LC, Blijlevens NM, Deutz NE, Donnelly JP, Lambin P, de Pauw BE: Monitoring myeloablative therapy-induced small bowel toxicity by serum citrulline concentration: a comparison with sugar permeability tests. Cancer 2005, 103:191-199.

161. Relja B, Szermutzky M, Henrich D, Maier M, de Haan JJ, Lubbers T, Buurman WA, Marzi I: Intestinal-FABP and liver-FABP: novel markers for severe abdominal injury. Acad Emerg Med 2010, 17:729-735.

162. Thuijls G, Derikx JP, van Wijck K, Zimmermann LJ, Degraeuwe PL, Mulder TL, Van der Zee DC, Brouwers HA, Verhoeven BH, van Heurn LW, Kramer BW, Buurman WA, Heineman E: Non-invasive markers for early diagnosis and determination of the severity of necrotizing enterocolitis. Ann Surg 2010 251:1174-1180.

163. Reisinger KW, Derikx JP, Thuijls G, van der Zee DC, Brouwers HA, van Bijnen AA, Wolfs TG, van Heurn LW, Buurman WA, Kramer BW: Noninvasive measurement of intestinal epithelial damage at time of refeeding can predict clinical outcome after necrotizing enterocolitis. Pediatr Res 2013, 73:209-213

164. Monbaliu D, de Vries B, Crabbé T, van Heurn E, Verwaest C, Roskams T, Fevery J, Pirenne J, Buurman WA: Liver fatty acid-binding protein: an early and sensitive plasma marker of hepatocellular damage and a reliable predictor of graft viability after liver transplantation from non-heartbeating donors. Transplant Proc 2005, 37:413-416.

165. Vreugdenhil AC, Wolters VM, Adriaanse MP, Van den Neucker AM, van Bijnen AA, Houwen R, Buurman WA: Additional value of serum I-FABP levels for evaluating celiac disease activity in children. Scand J Gastroenterol 2011, 46:1435-1441.

166. Adriaanse MP, Tack GJ, Passos VL, Damoiseaux JG, Schreurs MW, van Wijck K, Riedl RG, Masclee AA, Buurman WA, Mulder CJ, Vreugdenhil AC: Serum I-FABP as marker for enterocyte damage in coeliac disease and its relation to villous atrophy and circulating autoantibodies. Aliment Pharmacol Ther 2013, 37:482-490.

167. Delaney CP, O'Neill S, Manning F, Fitzpatrick JM, Gorey TF: Plasma concentrations of glutathione S-transferase isoenzyme are raised in patients with intestinal ischaemia. Br J Surg 1999, 86:1349-1353.

168. Gearhart SL, Delaney CP, Senagore AJ, Banbury MK, Remzi FH, Kiran RP Fazio WW: Prospective assessment of the predictive value of alphaglutathione S-transferase for intestinal ischemia. Am Surg 2003, 69:324-329.

169. Fagerhol MK: Calprotectin, a faecal marker of organic gastrointestinal abnormality. Lancet 2000, 356:1783-1784.

170. Lundberg JO, Hellström PM, Fagerhol MK, Weitzberg E, Roseth AG Technology insight: calprotectin, lactoferrin and nitric oxide as novel markers of inflammatory bowel disease. Nat Clin Pract Gastroenterol Hepatol 2005, 2:96-102.

171. Damms A, Bischoff SC: Validation and clinical significance of a new calprotectin rapid test for the diagnosis of gastrointestinal diseases. Int J Colorectal Dis 2008, 23:985-992

172. Lebreton C, Ménard S, Abed J, Moura IC, Coppo R, Dugave C, Monteiro RC, Fricot A, Traore MG, Griffin M, Cellier C, Malamut G, Cerf-Bensussan N, Heyman M: Interactions among secretory immunoglobulin A, CD71, and transglutaminase-2 affect permeability of intestinal epithelial cells to gliadin peptides. Gastroenterology 2012, 143:698-707. 
173. Wehkamp J, Koslowski M, Wang G, Stange EF: Barrier dysfunction due to distinct defensin deficiencies in small intestinal and colonic Crohn's disease. Mucosal Immunol 2008, Suppl 1:S67-S74.

174. Campeotto F, Baldassarre M, Laforgia N, Viallon V, Kalach N, Amati L, Butel MJ, Dupont C, Kapel N: Fecal expression of human $\beta$-defensin-2 following birth. Neonatology 2010, 98:365-369.

175. Fasano A, Not T, Wang W, Uzzau S, Berti I, Tommasini A, Goldblum SE: Zonulin, a newly discovered modulator of intestinal permeability, and its expression in coeliac disease. Lancet 2000, 355:1518-1519.

176. Heyman M, Abed J, Lebreton C, Cerf-Bensussan N: Intestinal permeability in coeliac disease: insight into mechanisms and relevance to pathogenesis. Gut 2012, 61:1355-1364.

177. May GR, Sutherland LR, Meddings JB: Is small intestinal permeability really increased in relatives of patients with Crohn's disease? Gastroenterology 1993, 104:1627-1632.

178. Petit CS, Barreau F, Besnier L, Gandille P, Riveau B, Chateau D, Roy M, Berrebi D, Svrcek M, Cardot P, Rousset M, Clair C, Thenet S: Requirement of cellular prion protein for intestinal barrier function and mislocalization in patients with inflammatory bowel disease. Gastroenterology 2012, 143:122-132.

179. Duckworth CA, Watson AJ: Analysis of epithelial cell shedding and gaps in the intestinal epithelium. Methods Mol Biol 2011, 763:105-114.

180. Edmunds SJ, Roy NC, Love DR, Laing WA: Kiwifruit extracts inhibit cytokine production by lipopolysaccharide-activated macrophages, and intestinal epithelial cells isolated from IL10 gene deficient mice. Cell Immunol 2011, 270:70-79.

181. Biasi F, Astegiano M, Maina M, Leonarduzzi G, Poli G: Polyphenol supplementation as a complementary medicinal approach to treating inflammatory bowel disease. Curr Med Chem 2011, 18:4851-4865.

182. Jung $M$, Triebel $S$, Anke $T$, Richling $E$, Erkel G: Influence of apple polyphenols on inflammatory gene expression. Mol Nutr Food Res 2009, 53:1263-1280.

183. Rembacken BJ, Snelling AM, Hawkey PM, Chalmers DM, Axon AT: Nonpathogenic Escherichia coli versus mesalazine for the treatment of ulcerative colitis: a randomised trial. Lancet 1999, 354:635-639.

184. Kruis W, Fric P, Pokrotnieks J, Lukás M, Fixa B, Kascák M, Kamm MA, Weismueller J, Beglinger C, Stolte M, Wolff C, Schulze J: Maintaining remission of ulcerative colitis with the probiotic Escherichia coli Nissle 1917 is as effective as with standard mesalazine. Gut 2004, 53:1617-1623.

185. Gionchetti P, Rizzello F, Venturi A, Brigidi P, Matteuzzi D, Bazzocchi G, Poggioli G, Miglioli M, Campieri M: Oral bacteriotherapy as maintenance treatment in patients with chronic pouchitis: a double-blind, placebocontrolled trial. Gastroenterology 2000, 119:305-309.

186. Gionchetti P, Rizzello F, Helwig U, Venturi A, Lammers KM, Brigidi P, Vitali B, Poggioli G, Miglioli M, Campieri M: Prophylaxis of pouchitis onset with probiotic therapy: a double-blind, placebo-controlled trial. Gastroenterology 2003, 124:1202-1209.

187. Bibiloni R, Fedorak RN, Tannock GW, Madsen KL, Gionchetti P, Campieri M, De Simone C, Sartor RB: VSL\#3 probiotic-mixture induces remission in patients with active ulcerative colitis. Am J Gastroenterol 2005, 100:1539-1546.

188. Miele E, Pascarella F, Giannetti E, Quaglietta L, Baldassano RN, Staiano A: Effect of a probiotic preparation (VSL\#3) on induction and maintenance of remission in children with ulcerative colitis. Am J Gastroenterol 2009, 104:437-443.

189. Oliva S, Di Nardo G, Ferrari F, Mallardo S, Rossi P, Patrizi G, Cucchiara S, Stronati L: Randomised clinical trial: the effectiveness of Lactobacillus reuteri ATCC 55730 rectal enema in children with active distal ulcerative colitis. Aliment Pharmacol Ther 2012, 35:327-334

190. Garcia Vilela E, De Lourdes De Abreu Ferrari M, Oswaldo Da Gama Torres H, Guerra Pinto A, Carolina Carneiro Aguirre A, Paiva Martins F, Marcos Andrade Goulart E, Sales Da Cunha A: Influence of Saccharomyces boulardii on the intestinal permeability of patients with Crohn's disease in remission. Scand J Gastroenterol 2008, 43:842-848.

191. Patel RM, Myers LS, Kurundkar AR, Maheshwari A, Nusrat A, Lin PW: Probiotic bacteria induce maturation of intestinal claudin 3 expression and barrier function. Am J Pathol 2012, 180:626-635.

192. Camilleri M, Lasch K, Zhou W: Irritable bowel syndrome: methods, mechanisms, and pathophysiology: the confluence of increased permeability, inflammation, and pain in irritable bowel syndrome. Am J Physiol Gastrointest Liver Physiol 2012, 303:G775-G785.
193. Martínez C, Lobo B, Pigrau M, Ramos L, González-Castro AM, Alonso C, Guilarte M, Guilá M, de Torres I, Azpiroz F, Santos J, Vicario M: Diarrhoeapredominant irritable bowel syndrome: an organic disorder with structural abnormalities in the jejunal epithelial barrier. Gut 2013, 62:1160-1168

194. Piche T, Barbara G, Aubert P, Bruley des Varannes S, Dainese R, Nano JL, Cremon C, Stanghellini V, De Giorgio R, Galmiche JP, Neunlist M: Impaired intestinal barrier integrity in the colon of patients with irritable bowel syndrome: involvement of soluble mediators. Gut 2009, 58:196-201.

195. Barbara G, Cremon C, Carini G, Bellacosa L, Zecchi L, De Giorgio R, Corinaldesi $R$, Stanghellini $V$ : The immune system in irritable bowel syndrome. J Neurogastroenterol Motil 2011, 17:349-359.

196. Coëffier M, Gloro R, Boukhettala N, Aziz M, Lecleire S, Vandaele N, Antonietti M, Savoye G, Bôle-Feysot C, Déchelotte P, Reimund JM, Ducrotté P: Increased proteasome-mediated degradation of occludin in irritable bowel syndrome. Am J Gastroentero/ 2010, 105:1181-1188.

197. Bischoff SC: Food allergy and eosinophilic gastroenteritis and colitis. Curr Opin Allergy Clin Immunol 2010, 10:238-245.

198. Vivinus-Nébot M, Dainese R, Anty R, Saint-Paul MC, Nano JL, Gonthier N, Marjoux S, Frin-Mathy G, Bernard G, Hébuterne X, Tran A, Theodorou V, Piche T: Combination of allergic factors can worsen diarrheic irritable bowel syndrome: role of barrier defects and mast cells. Am J Gastroenterol 2012, 107:75-81.

199. Barbara G, Wang B, Stanghellini V, de Giorgio R, Cremon C, Di Nardo G, Trevisani M, Campi B, Geppetti P, Tonini M, Bunnett NW, Grundy D, Corinaldesi R: Mast cell-dependent excitation of visceral-nociceptive sensory neurons in irritable bowel syndrome. Gastroenterology 2007, 132:26-37.

200. Bühner S, Li Q, Vignali S, Barbara G, De Giorgio R, Stanghellini V, Cremon C, Zeller F, Langer R, Daniel H, Michel K, Schemann M: Activation of human enteric neurons by supernatants of colonic biopsy specimens from patients with irritable bowel syndrome. Gastroenterology 2009, 137:1425-1434.

201. Cremon C, Carini G, Wang B, Vasina V, Cogliandro RF, De Giorgio R, Stanghellini V, Grundy D, Tonini M, De Ponti F, Corinaldesi R, Barbara G: Intestinal serotonin release, sensory neuron activation, and abdominal pain in irritable bowel syndrome. Am J Gastroenterol 2011, 106:1290-1298

202. Brown PM, Drossman DA, Wood AJ, Cline GA, Frazier KS, Jackson Jl, Bronner J, Freiman J, Zambrowicz B, Sands A, Gershon MD: The tryptophan hydroxylase inhibitor LX1031 shows clinical benefit in patients with nonconstipating irritable bowel syndrome. Gastroenterology 2011, 141:507-516.

203. Klooker TK, Braak B, Koopman KE, Welting O, Wouters MM, van der Heide S, Schemann M, Bischoff SC, van den Wijngaard RM, Boeckxstaens GE: The mast cell stabiliser ketotifen decreases visceral hypersensitivity and improves intestinal symptoms in patients with irritable bowel syndrome. Gut 2010, 59:1213-1221.

204. Heizer WD, Southern S, McGovern S: The role of diet in symptoms of irritable bowel syndrome in adults: a narrative review. J Am Diet Assoc 2009, 109:1204-1214

205. Clarke G, Cryan JF, Dinan TG, Quigley EM: Review article: probiotics for the treatment of irritable bowel syndrome-focus on lactic acid bacteria. Aliment Pharmacol Ther 2012, 35:403-413.

206. Whelan K: Probiotics and prebiotics in the management of irritable bowel syndrome: a review of recent clinical trials and systematic reviews. Curr Opin Clin Nutr Metab Care 2011, 14:581-587.

207. DuPont AW, DuPont HL: The intestinal microbiota and chronic disorders of the gut. Nat Rev Gastroenterol Hepatol 2011, 8:523-531.

208. Brenner DM, Moeller MJ, Chey WD, Schoenfeld PS: The utility of probiotics in the treatment of irritable bowel syndrome: a systematic review. Am J Gastroenterol 2009, 104:1033-1049.

209. Hoveyda N, Heneghan C, Mahtani KR, Perera R, Roberts N, Glasziou P: A systematic review and meta-analysis: probiotics in the treatment of irritable bowel syndrome. BMC Gastroenterol 2009, 9:15.

210. Francavilla R, Miniello V, Magistà AM, De Canio A, Bucci N, Gagliardi F, Lionetti E, Castellaneta S, Polimeno L, Peccarisi L, Indrio F, Cavallo L: A randomized controlled trial of Lactobacillus GG in children with functional abdominal pain. Pediatrics 2010, 126:e1445-e1452.

211. Zeng J, Li YQ, Zuo XL, Zhen YB, Yang J, Liu CH: Clinical trial: effect of active lactic acid bacteria on mucosal barrier function in patients with 
diarrhoea-predominant irritable bowel syndrome. Aliment Pharmacol Ther 2008, 28:994-1002

212. Schmulson $M$, Chang $L$ : Review article: the treatment of functional abdominal bloating and distension. Aliment Pharmacol Ther 2011, 33:1071-1086.

213. Burcelin R, Crivelli V, Dacosta A, Roy-Tirelli A, Thorens B: Heterogeneous metabolic adaptation of C57BL/6 J mice to high-fat diet. Am J Physio Endocrinol Metab 2002, 282:E834-E842.

214. Lam YY, Ha CW, Campbell CR, Mitchell AJ, Dinudom A, Oscarsson J, Cook DI, Hunt NH, Caterson ID, Holmes AJ, Storlien LH: Increased gut permeability and microbiota change associate with mesenteric fat inflammation and metabolic dysfunction in diet-induced obese mice. PLoS One 2012, 7:e34233

215. Ley RE, Turnbaugh PJ, Klein S, Gordon J: Microbial ecology: human gut microbes associated with obesity. Nature 2006, 444:1022-1023.

216. Turnbaugh PJ, Ley RE, Mahowald MA, Magrini V, Mardis ER, Gordon Jl: An obesity-associated gut microbiome with increased capacity for energy harvest. Nature 2006, 444:1027-1031.

217. Qin J, Li Y, Cai Z, Li S, Zhu J, Zhang F, Liang S, Zhang W, Guan Y, Shen D, Peng Y, Zhang D, Jie Z, Wu W, Qin Y, Xue W, Li J, Han L, Lu D, Wu P, Dai Y, Sun X, Li Z, Tang A, Zhong S, Li X, Chen W, Xu R, Wang M, Feng Q, et al: A metagenome-wide association study of gut microbiota in type 2 diabetes. Nature 2012, 490:55-60.

218. Bäckhed F, Ding H, Wang T, Hooper LV, Koh GY, Nagy A, Semenkovich CF, Gordon Jl: The gut microbiota as an environmental factor that regulates fat storage. Proc Natl Acad Sci U S A 2004, 101:15718-15723.

219. Cani PD, Delzenne NM: Interplay between obesity and associated metabolic disorders: new insights into the gut microbiota. Curr Opin Pharmacol 2009, 9:737-743.

220. Tremaroli V, Bäckhed F: Functional interactions between the gut microbiota and host metabolism. Nature 2012, 489:242-249.

221. de Munter JS, Hu FB, Spiegelman D, Franz M, van Dam RM: Whole grain, bran, and germ intake and risk of type 2 diabetes: a prospective cohort study and systematic review. PLoS Med 2007, 4:e261.

222. Park Y, Subar AF, Hollenbeck A, Schatzkin A: Dietary fiber intake and mortality in the NIH-AARP diet and health study. Arch Intern Med 2011, $171: 1061-1068$.

223. Després JP, Lemieux I: Abdominal obesity and metabolic syndrome. Nature 2006, 444:881-887.

224. Donath MY, Shoelson SE: Type 2 diabetes as an inflammatory disease. Nat Rev Immunol 2011, 11:98-107.

225. Brooks GC, Blaha MJ, Blumenthal RS: Relation of C-reactive protein to abdominal adiposity. Am J Cardiol 2010, 106:56-61.

226. Cusi K: Role of obesity and lipotoxicity in the development of nonalcoholic steatohepatitis: pathophysiology and clinical implications. Gastroenterology 2012, 142:711-725.

227. Amar J, Chabo C, Waget A, Klopp P, Vachoux C, Bermúdez-Humarán LG, Smirnova N, Bergé M, Sulpice T, Lahtinen S, Ouwehand A, Langella $P$, Rautonen N, Sansonetti PJ, Burcelin R: Intestinal mucosal adherence and translocation of commensal bacteria at the early onset of type 2 diabetes: molecular mechanisms and probiotic treatment. EMBO Mol Med 2011, 3:559-572.

228. Farhadi A, Gundlapalli S, Shaikh M, Frantzides C, Harrell L, Kwasny MM, Keshavarzian A: Susceptibility to gut leakiness: a possible mechanism for endotoxaemia in non-alcoholic steatohepatitis. Liver Int 2008, 28:1026-1033.

229. Brignardello J, Morales P, Diaz E, Romero J, Brunser O, Gotteland M: Pilot study: alterations of intestinal microbiota in obese humans are not associated with colonic inflammation or disturbances of barrier function. Aliment Pharmacol Ther 2010, 32:1307-1314

230. Tsilingiri K, Barbosa T, Penna G, Caprioli F, Sonzogni A, Viale G, Rescigno M: Probiotic and postbiotic activity in health and disease: comparison on a novel polarised ex-vivo organ culture model. Gut 2012, 61:1007-1015.

231. Cani PD, Possemiers S, Van de Wiele T, Guiot Y, Everard A, Rottier O, Geurts L, Naslain D, Neyrinck A, Lambert DM, Muccioli GG, Delzenne NM: Changes in gut microbiota control inflammation in obese mice through a mechanism involving GLP-2-driven improvement of gut permeability. Gut 2009, 58:1091-1103.

232. Jumpertz R, Le DS, Turnbaugh PJ, Trinidad C, Bogardus C, Gordon Jl, Krakoff $\mathrm{J}$ : Energy-balance studies reveal associations between gut microbes, caloric load, and nutrient absorption in humans. Am J Clin Nutr 2011, 94:58-65.
233. Santacruz A, Collado MC, García-Valdés L, Segura MT, Martín-Lagos JA, Anjos T, Martí-Romero M, Lopez RM, Florido J, Campoy C, Sanz Y: Gut microbiota composition is associated with body weight, weight gain and biochemical parameters in pregnant women. Br J Nutr 2010, 104:83-92.

234. Delzenne NM, Neyrinck AM, Bäckhed F, Cani PD: Targeting gut microbiota in obesity: effects of prebiotics and probiotics. Nat Rev Endocrinol 2011, 7:639-646

235. Dewulf EM, Cani PD, Claus SP, Fuentes S, Puylaert PG, Neyrinck AM, Bindels LB, de Vos WM, Gibson GR, Thissen JP, Delzenne NM: Insight into the prebiotic concept: lessons from an exploratory, double blind intervention study with inulin-type fructans in obese women. Gut 2013, 62:1112-1121.

236. Swank GM, Deitch EA: Role of the gut in multiple organ failure: bacterial translocation and permeability changes. World J Surg 1996, 20:411-417.

237. Derikx JP, van Waardenburg DA, Thuijls G, Willigers HM, Koenraads M, van Bijnen AA, Heineman E, Poeze M, Ambergen T, van Ooij A, van Rhijn LW, Buurman WA: New insight in loss of gut barrier during major nonabdominal surgery. PLoS One 2008, 3:e3954.

238. Derikx JP, Bijker EM, Vos GD, van Bijnen AA, Heineman E, Buurman WA, van Waardenburg DA: Gut mucosal cell damage in meningococcal sepsis in children: relation with clinical outcome. Crit Care Med 2010, 38:133-137.

239. de Haan JJ, Lubbers T, Derikx JP, Relja B, Henrich D, Greve JW, Marzi I, Buurman WA: Rapid outcome development of intestinal cell damage following severe trauma: a prospective observational cohort study. Crit Care 2009, 13:R86.

240. Derikx JP, van Waardenburg DA, Granzen B, van Bijnen AA, Heineman E, Buurman WA: Detection of chemotherapy-induced enterocyte toxicity with circulating intestinal fatty acid binding protein. J Pediatr Hematol Oncol 2006, 28:267-269.

241. Hanssen SJ, Derikx JP, Vermeulen Windsant IC, Heijmans JH, Koeppel TA, Schurink GW, Buurman WA, Jacobs MJ: Visceral injury and systemic inflammation in patients undergoing extracorporeal circulation during aortic surgery. Ann Surg 2008, 248:117-125.

242. van Wijck K, Lenaerts $K$, van Loon LJ, Peters WH, Buurman WA, Dejong $\mathrm{CH}$ : Exercise-induced splanchnic hypoperfusion results in gut dysfunction in healthy men. PLoS One 2011, 6:e22366.

243. Thuijls G, van Wijck K, Grootjans J, Derikx JP, van Bijnen AA, Heineman E, Dejong $\mathrm{CH}$, Buurman WA, Poeze M: Early diagnosis of intestinal ischemia using urinary and plasma fatty acid binding proteins. Ann Surg 2011, 253:303-308.

244. van Wijck K, Lenaerts K, Grootjans J, Wijnands KA, Poeze M, van Loon LJ, Dejong $\mathrm{CH}$, Buurman WA: Physiology and pathophysiology of splanchnic hypoperfusion and intestinal injury during exercise: strategies for evaluation and prevention. Am J Physiol Gastrointest Liver Physiol 2012, 303: G155-G168

245. Grootjans J, Hodin CM, de Haan JJ, Derikx JP, Rouschop KM, Verheyen FK, van Dam RM, Dejong CH, Buurman WA, Lenaerts K: Level of activation of the unfolded protein response correlates with Paneth cell apoptosis in human small intestine exposed to ischemia/reperfusion. Gastroenterology 2011, 140:529-539.

246. Grootjans J, Hundscheid IH, Lenaerts K, Boonen B, Renes IB, Verheyen FK, Dejong $\mathrm{CH}$, von Meyenfeldt MF, Beets GL, Buurman WA: Ischaemiainduced mucus barrier loss and bacterial penetration are rapidly counteracted by increased goblet cell secretory activity in human and rat colon. Gut 2013, 62:250-258.

247. Grootjans J, Thuijls G, Derikx JP, van Dam RM, Dejong CH, Buurman WA: Rapid lamina propria retraction and zipper-like constriction of the epithelium preserves the epithelial lining in human small intestine exposed to ischaemia-reperfusion. J Pathol 2011, 224:411-419.

248. Derikx JP, Matthijsen RA, de Bruïne AP, van Dam RM, Buurman WA, Dejong $\mathrm{CH}$ : A new model to study intestinal ischemia-reperfusion damage in man. J Surg Res 2011, 166:222-226.

249. Rayes N, Seehofer D, Hansen S, Boucsein K, Müller AR, Serke S, Bengmark S, Neuhaus P: Early enteral supply of lactobacillus and fiber versus selective bowel decontamination: a controlled trial in liver transplant recipients. Transplantation 2002, 74:123-127.

250. Rayes N, Seehofer D, Theruvath T, Schiller RA, Langrehr JM, Jonas S, Bengmark S, Neuhaus P: Supply of pre- and probiotics reduces bacterial infection rates after liver transplantation - a randomized, double-blind trial. Am J Transplant 2005, 5:125-130.

251. Rayes N, Seehofer D, Theruvath T, Mogl M, Langrehr JM, Nüssler NC, Bengmark S, Neuhaus P: Effect of enteral nutrition and synbiotics on bacterial infection 
rates after pylorus-preserving pancreatoduodenectomy: a randomized, double-blind trial. Ann Surg 2007, 246:36-41.

252. Oláh A, Belágyi T, Issekutz A, Gamal ME, Bengmark S: Randomized clinical trial of specific lactobacillus and fibre supplement to early enteral nutrition in patients with acute pancreatitis. Br J Surg 2002, 89:1103-1107.

253. Oláh A, Belágyi T, Pótó L, Romics L Jr, Bengmark S: Synbiotic control of inflammation and infection in severe acute pancreatitis: a prospective, randomized, double blind study. Hepatogastroenterology 2007, 54:590-594.

254. Besselink MG, van Santvoort HC, Buskens E, Boermeester MA, van Goor H, Timmerman HM, Nieuwenhuijs VB, Bollen TL, van Ramshorst B, Witteman BJ, Rosman C, Ploeg RJ, Brink MA, Schaapherder AF, Dejong CH, Wahab PJ, van Laarhoven CJ, van der Harst E, van Eijck CH, Cuesta MA, Akkermans LM, Gooszen HG: Probiotic prophylaxis in predicted severe acute pancreatitis: a randomised, double-blind, placebo-controlled trial. Lancet 2008, 371:651-659.

255. Morrow LE: Probiotics in the intensive care unit. Curr Opin Crit Care 2009, 15:144-148.

256. Barraud D, Bollaert PE, Gibot S: Impact of the Administration of Probiotics on Mortality in Critically III Adult Patients: a meta-analysis of randomized controlled trials. Chest 2013, 143:646-655.

257. Arthur JC, Perez-Chanona E, Mühlbauer M, Tomkovich S, Uronis JM, Fan TJ, Campbell BJ, Abujamel T, Dogan B, Rogers AB, Rhodes JM, Stintzi A, Simpson KW, Hansen JJ, Keku TO, Fodor AA, Jobin C: Intestinal inflammation targets cancer-inducing activity of the microbiota. Science 2012, 338:120-123.

258. Scher JU, Abramson SB: The microbiome and rheumatoid arthritis. Nat Rev Rheumatol 2011, 7:569-578.

259. Mattila E, Uusitalo-Seppälä R, Wuorela M, Lehtola L, Nurmi H, Ristikankare M, Moilanen V, Salminen K, Seppälä M, Mattila PS, Anttila VJ, Arkkila P: Fecal transplantation, through colonoscopy, is effective therapy for recurrent Clostridium difficile infection. Gastroenterology 2012, 142:490-496.

260. Brandt $\sqcup$, Aroniadis OC, Mellow M, Kanatzar A, Kelly C, Park T, Stollman N, Rohlke F, Surawicz C: Long-term follow-up of colonoscopic fecal microbiota transplant for recurrent Clostridium difficile infection. Am J Gastroenterol 2012, 107:1079-1087.

261. Larsen TM, Dalskov SM, van Baak M, Jebb SA, Papadaki A, Pfeiffer AF, Martinez JA, Handjieva-Darlenska T, Kunešová M, Pihlsgård M, Stender $S$, Holst C, Saris WH, Astrup A: Diets with high or low protein content and glycemic index for weight-loss maintenance. N Engl J Med 2010, 363:2102-2113.

262. Volynets V, Machann J, Küper MA, Maier IB, Spruss A, Königsrainer A Bischoff SC, Bergheim I: A moderate weight reduction through dietary intervention decreases hepatic fat content in patients with non-alcoholic fatty liver disease (NAFLD): a pilot study. Eur J Nutr 2013, 52:527-535.

263. Barrett JS, Gearry RB, Muir JG, Irving PM, Rose R, Rosella O, Haines ML, Shepherd SJ, Gibson PR: Dietary poorly absorbed, short-chain carbohydrates increase delivery of water and fermentable substrates to the proximal colon. Aliment Pharmacol Ther 2010, 31:874-882.

264. Rijkers GT, de Vos WM, Brummer RJ, Morelli L, Corthier G, Marteau P: Health benefits and health claims of probiotics: bridging science and marketing. Br J Nutr 2011, 106:1291-1296.

265. Hoffmann DE: Health claim regulation of probiotics in the USA and the EU: is there a middle way? Benef Microbes 2013, 4:109-115.

\section{Submit your next manuscript to BioMed Central and take full advantage of:}

- Convenient online submission

- Thorough peer review

- No space constraints or color figure charges

- Immediate publication on acceptance

- Inclusion in PubMed, CAS, Scopus and Google Scholar

- Research which is freely available for redistribution

Submit your manuscript at www.biomedcentral.com/submit
C Biomed Central 